\title{
Burn severity mapping from Landsat MESMA fraction images and Land Surface Temperature
}

\author{
Carmen Quintano $^{\mathrm{a}, \mathrm{b}}{ }^{*}$, Alfonso Fernandez-Manso $^{\mathrm{c}}$, Dar A. Roberts ${ }^{\mathrm{d}}$ \\ a Electronic Technology Department, University of Valladolid, C/Francisco Mendizábal, s/n, 47014 Valladolid, Spain \\ b Sustainable Forest Management Research Institute, University of Valladolid, Spanish National Institute for Agricultural and Food Research and Technology, Spain \\ c Agrarian Science and Engineering Department, University of León, Av. Astorga s/n. 24400 Ponferrada, Spain \\ d Department of Geography, University of California, Santa Barbara, CA 93106, United States
}

\section{A R T I C L E I N F O}

\section{Article history:}

Received 11 February 2016

Received in revised form 29 November 2016

Accepted 13 December 2016

Available online $\mathrm{xxx}$

\section{Keywords}

Burn severity

MESMA

LST

MLR

Landsat

Mediterranean forest ecosystems

\begin{abstract}
A B S T R A C T
Forest fires are incidents of great importance in Mediterranean environments. Landsat data have proven to be suitable for evaluating post-fire vegetation damage and determining different levels of burn severity, which is crucial for planning post-fire rehabilitation. This study assessed the utility of combined Multiple Endmember Spectral Mixture Analysis (MESMA) fraction images and Land Surface Temperature (LST) to accurately map burn severity. We studied a large convection-dominated wildfire, which occurred on 19-21 September 2012 in Spain, in a zone dominated by Pinus pinaster Ait. Burn severity degree (low, moderate, and high) was measured 2-3 months after fire in 111 field plots using the Composite Burn Index (CBI). Four fraction images were generated using MESMA from the reflective bands of a post-fire Landsat 7 Enhanced Thematic Mapper (ETM +) image: 1.-char, 2.-green vegetation (GV), 3.-non-photosynthetic vegetation and soil (NPVS) and 4.-shade. The thermal band was converted to LST using a single channel algorithm. Next, Multinomial Logistic Regression (MLR) was used to obtain the probability of each burn severity level from MESMA fraction images and LST. Finally, a burn severity map was generated from the probability images and independently validated using an error matrix, producer and user accuracies per class, and $\kappa$ statistic. MLR identified the char fraction image and LST as the only significant explanatory variables when burn severity acted as the response variable. Two burn severity degrees (low-moderate and high) were finally considered to build the final burn severity map. In this way, we reached a higher accuracy $(\kappa=0.79)$ than using the original three burn severity levels $(\kappa=0.66)$. Our study demonstrates the validity of combining fraction images and LST from Landsat data to map burn severity accurately in Mediterranean countries.
\end{abstract}

C) 2016 Published by Elsevier Ltd.

\section{Introduction}

Wildfires have significant ecological and biophysical repercussions in almost all terrestrial ecosystems (Chuvieco, 2009; Pyne, 1996; Veraverbeke et al., 2012a). Specifically in Mediterranean countries (Portugal, Spain, France, Italy and Greece) fires are a substantial source of land degradation, burning an average of $>0.4$ million hectares based on a 35-year average as reported by the Joint Research Centre (JRC) of the European Commission (Schmuck et al., 2014). Accurate knowledge of the spatial distribution of burn severity levels is crucial to plan and execute post-fire management activities (mainly soil stabilization and vegetation rehabilitation) (Frolking et al., 2009; Lentile et al., 2006). Compared to field efforts required to directly measure the post-fire burn effects, remote sensing based measures are a more affordable option and are especially suitable for monitoring large and topographically complex landscapes (Chuvieco, 2009). Fire severity studies, in particular, have been widely based on

* Corresponding author at: Electronic Technology Department, University of Valladolid, C/Francisco Mendizábal, s/n, 47014 Valladolid, Spain.

Email addresses: menchu@tele.uva.es (C. Quintano); alfonso.manso@unileon.es (A. Fernandez-Manso); dar@geog.ucsb.edu (D.A. Roberts) the remotely sensed data acquired by sensors onboard the series of Landsat satellites (Brewer et al., 2005; Chu et al., 2016; Cocke et al., 2005; Fang and Yang, 2014; Fernández-Manso and Quintano, 2015; Parker et al., 2015; Quintano et al., 2013; Wu et al., 2015; Veraverbeke and Hook, 2013). The main advantages of Landsat imagery include multispectral sampling ( 6 reflective bands and one thermal band), moderate spatial resolution and image time series covering $>40$ years (Fang and Yang, 2014).

Remote sensing based methods to study burn severity are based mainly on spectral indices (Arnett et al., 2015; Chu et al., 2016; Fernández-Manso and Quintano, 2015; Soverel et al., 2011; Stambaugh et al., 2015; Tanase et al., 2011), radiative transfer models (RTM, Chuvieco et al., 2006; Chuvieco et al., 2007; de Santis and Chuvieco, 2007; de Santis et al., 2009), or spectral mixture analysis (SMA, Fernández-Manso et al., 2009; Lentile et al., 2006, 2009; Quintano et al., 2013; Sunderman and Weisberg, 2011). Regarding spectral indices, many burn severity studies are based on the normalized burn ratio (NBR). Differenced NBR (dNBR) is widely used and can be seen as a reference to map burn severity (Chu et al., 2016; Fang and Yang, 2014; Key and Benson, 2006; Soverel et al., 2010). Relative dNBR (RdNBR) a modification of dNBR initially proposed by Miller and Thode (2007) may be, however, a superior way of performing burn severity comparisons among regions and for estimating 
burn severity where pre-fire vegetative cover is low (Cansler and McKenzie, 2012; Kane et al., 2013; Miller et al., 2009; Stambaugh et al., 2015). A new modification of dNBR, the relativized burn ratio (RBR), has been recently proposed by Parks et al. (2014) as a substitute to both RdNBR and dNBR for estimating burn severity. However, some recent studies (Kolden et al., 2015; Sparks et al., 2015) are pointing out some limitations of all the Monitoring Trends in Burn Severity (MTBS) products (based on the previous mentioned spectral indexes). Equally, previous studies (Kasischke et al., 2007; Roy et al., 2006) identified some shortcomings of NBR derived indices. Roy et al. (2006) showed that NBR was not optimal in quantifying fire severity shortly after fire occurrence, and Kasischke et al. (2007) found that NBR derived indices did not displayed a high correlation with burn severity as measured by the Composite Burn Index (CBI, Key and Benson, 2006).

RTM models have been proposed to solve the limitation in accuracy and precision of previous burn severity studies and improve the estimation of burn severity form satellite data (de Santis et al., 2009). They simulate spectral signatures from a set of input parameters (Leaf Area Index, percentage of dry leaves, and CBI values using just two vegetation strata), providing a physically based approach to assess burn severity. As described by de Santis et al. (2009), in the forward simulation mode, RTMs calculate the effects of such plant parameters to generate simulated spectral reflectance. In the inverse mode, spectra from remotely sensed data are fit against forward modeled spectra to estimate some of those plant parameters. The use of RTMs in the forward mode to simulate burn severity scenarios (in terms of $\mathrm{CBI}$ ) was proposed by Chuvieco et al. (2006). De Santis and Chuvieco (2007) used the same simulation scenario in the inverse mode to estimate $\mathrm{CBI}$ values from a large forest fire.

Finally, many studies have used fraction images from SMA to map burn severity as well (Fernández-Manso et al., 2009; Lentile et al., 2006, 2009; Sunderman and Weisberg, 2011; Veraverbeke and Hook, 2013). Post-fire environments are usually composed of a mixture of ash, vegetation and soil immediately after a fire. For that reason, monitoring post-fire effects using medium spatial resolution sensors such as Landsat can be contemplated as a sub-pixel question. The SMA based method uses potentially all reflective bands of remotely sensed satellite imagery, whereas spectral index based approaches make use of just two spectral bands (Sunderman and Weisberg, 2011). Assuming linear SMA, the reflectance of a mixed pixel may be considered as a linear combination of the endmembers reflectance, weighted by the fractional area of each endmember in the pixel (Roberts et al., 1993). Spectral unmixing can be implemented using different approaches. Modified Gramm-Schmidt orthogonal decomposition (Adams et al., 1993), least squares (Shimabukuro and Smith, 1991) and singular value decomposition (Boardman et al., 1995) are three of the most commonly used; and root mean square error (RMSE) is the most frequently used method to evaluate model fit. SMA is restricted to the same set of endmembers to unmix the whole image whether or not such endmembers exist in the pixel. By contrast, Multiple Endmember SMA (MESMA) (Roberts et al., 1998) may use a large number of endmembers to unmix a scene. MESMA accounts for within class spectral variability as each pixel may be unmixed by a different combination of potential endmembers. A few recent studies (Veraverbeke and Hook, 2013; Veraverbeke et al., 2014) have confirmed that MESMA fraction images show a high correlation with field measured burn severity (often CBI). Our study will be based on MESMA factions as well but we will complement reflective information with thermal data, as Land Surface Temperature (LST) has recently been shown to be related to burn severity.
All of the studies that associated fire damage with LST (e.g. Lambin et al., 2003; Quintano et al., 2015; Veraverbeke et al., 2010; Vlassova et al., 2014; Wendt et al., 2007) reported a LST increase immediately following the fire. Lentile et al. (2006) stated that, although thermal infrared wavelengths are commonly discarded in burn severity studies, they may act as an indicator of the absence of evapotranspiration due to the presence of exposed soils after fire. Furthermore, analyzing fires in Mediterranean forest ecosystems, Quintano et al. (2015) confirmed that LST may be of considerable value as an indicator of burn severity. Similarly, other studies (e.g. Veraverbeke et al., 2012c; Vlassova et al., 2014) concluded that LST is an essential indicator to interpret immediately after fire the spatial variation of burn severity. Chen et al. (2015) concluded that the application of thermal infrared spectral bands (3.0-12.5 nm) augmented burn severity assessments versus using only mid infrared bands. Harris et al. (2011) concluded that the spectral index based on NBR and enhanced by LST (initially proposed by Veraverbeke et al., 2011) slightly outperformed NBR to assess burn severity in chaparral. Similarly, Zheng et al. (2016) proposed a new index based on LST and enhanced vegetation index (EVI) and showed that it performed equally well for post-fire areas covered with both sparse vegetation and dense vegetation and relatively better than some commonly used burn severity indices.

Quintano et al. (2013) concluded that MESMA fraction images enable accurate burn severity mapping in Spanish Mediterranean ecosystems. However, their study was not validated using field measured burn severity but post-fire ortho-photographs. Furthermore, Quintano et al. (2015) showed that Landsat LST may act as an indicator of burn severity, though a true burn severity map was not estimated from LST. Instead, the authors spatially represented predicted CBI from LST. This new study aims to confirm that MESMA fractions accurately map burn severity in Mediterranean ecosystems (ground measured as $\mathrm{CBI}$ ) and to demonstrate that LST is highly related to burn severity immediately following a fire and thus increases the accuracy of the MESMA-based burn severity map. Moreover, although both reflective and thermal information have a proven relationship to burn severity, there are no studies that have exploited them simultaneously, so our study is testing for the first time the potential of combined use to estimate burn severity. Our main goal is to evaluate whether LST complements MESMA fraction images to map burn severity accurately (more accurately that using just MESMA fractions). The specific objectives can be summarized as: 1) to verify that MESMA fraction images are related to field measured CBI and to determine which fraction image is superior for burn severity mapping; 2) to check whether a burn severity estimate based on both MESMA fraction images and LST is more accurate than burn severity estimate based solely on MESMA fraction images; and 3) to map accurately burn severity. We used Multinomial Logistic Regression (MLR) that has been used recently in different remote sensing based studies (Guccione et al., 2015; Marchetti et al., 2011; Mulder et al., 2013; Prabhakar et al., 2013a, 2013b; Tan et al., 2015; Vasques et al., 2015; Waser et al., 2014; Zeilhofer, 2006), but never to estimate burn severity from remotely sensed images to our knowledge. Moreover, the use of MLR gave us the opportunity of generating probability images of each burn severity level that are easy to interpret and can act as inputs to hard classifiers to create a burn severity map. We based our study on Landsat data that includes both types of information (reflective and thermal), which is an opportunity since there is no need to use different sensors. 


\section{Material}

\subsection{Study area}

A large fire burned $117.75 \mathrm{~km}^{2}$ in 'Castrocontigo' (Sierra del Teleno, northwestern Spain) between 19 and 21 August 2012. Small fires mainly caused by dry spring-summer storms have frequently affected this forest ecosystem. However, the 2012 fire, facilitated by the heat wave that affected the area, was a convection-dominated mega-fire predominated by a high burn severity level. This fire was included in the annual European report of fires by the Joint Research Centre of the European Commission due to its importance (Schmuck et al., 2012). Forest fires of such magnitude are uncommon in Europe, and even less in NW Spain. The Castrocontigo forest fire had two different characteristics that made it a singular case of study: 1.-It can be considered a 4th generation mega forest fire (fire crossing the interface urban-forest) (Costa et al., 2011); and 2.-It had a highly convective typology (Grillo et al., 2008). Both characteristics are related to socioeconomic and climatic factors that converge in the Teleno Mountains, causing that forest landscapes to evolve into vegetation structures with a higher combustible load, and horizontal and vertical continuity. These situations are becoming more frequent in Europe, so the study of the Castrocontigo forest fire may help in the prevention and the study of future fires of similar characteristics.

Sierra del Teleno (Fig. 1) is a small mountain chain with an average slope of approximately $10 \%$ and elevations ranging between 850 and $2100 \mathrm{~m}$ above sea level. The vegetation within the area affected by the fire is dominated by Pinus pinaster Ait. (73\%) coexisting with other Pinus species (Pinus nigra Arm., 3\%, and Pinus sylvestris L., 2\%) (Third Spanish National Forest Inventory, Alberdi et al., 2010). Additionally, $7 \%$ of the fire-affected area was covered by Quercus ilex L., 5\% by Quercus pyrenaica Willd. and $10 \%$ by shrubs. The average annual rainfall ranges between 650 and $900 \mathrm{~mm}$ and there is a summer dryness typical of a Mediterranean climate.

\subsection{Dataset}

\subsubsection{Field data}

The 2012 fall was especially dry and wood extraction was not occurring in the study area. These two facts suggest that post-fire conditions remained almost unchanged for the two-three months following the fire. Nine to twelve weeks following the fire, burn severity was measured in the field in $11,130 \mathrm{~m}$ diameter circular plots using the Composite Burn Index (CBI) (see Key and Benson, 2006 for a complete description). CBI is a method of assessing burn severity in the field specifically designed to validate $30-\mathrm{m}$ resolution Landsat-based burn-severity images. It combines ecologically significant variables related to burn severity into one numeric site index, and is becoming a standard to ground measure burn severity, although diverse studies have pointed out some of its limitations and have proposed some modification (e.g. the Geometrically Structured CBI, GeoCBI, by de Santis and Chuvieco, 2009, or weighted CBI, WCBI, by Soverel et al., 2010, 2011).

Although burn severity can be represented on a continuous scale by field measurement as CBI, these continuous metrics are usually grouped into different categories (Parks et al., 2014). In our study, the chosen categories were: unchanged, low, moderate, and high burn severity level. Our CBI thresholds for low, moderate and high burn severity classes were situated halfway between the values listed by Miller and Thode (2007) as a general guide, as many previous studies have used (e.g. Kane et al., 2014; Miller et al., 2009; Parker et al., 2015; Parks et al., 2014; Stambaugh et al., 2015): unburned (0.00), low burn severity $(0.10-1.24)$, moderate burn severity $(1.25-2.24)$ and high burn severity $(2.25-3.00)$. To locate the field plots, we searched areas with similar forest structure and fire effects and used a Global Positioning System (GPS) to georeference them. The number of study plots was proportional to the surface included in each severity level from the initial official severity map. Specifically, the field measured plots were grouped into four categories: unburned (27 plots), low severity ( 8 plots), moderate severity ( 29 plots) and high

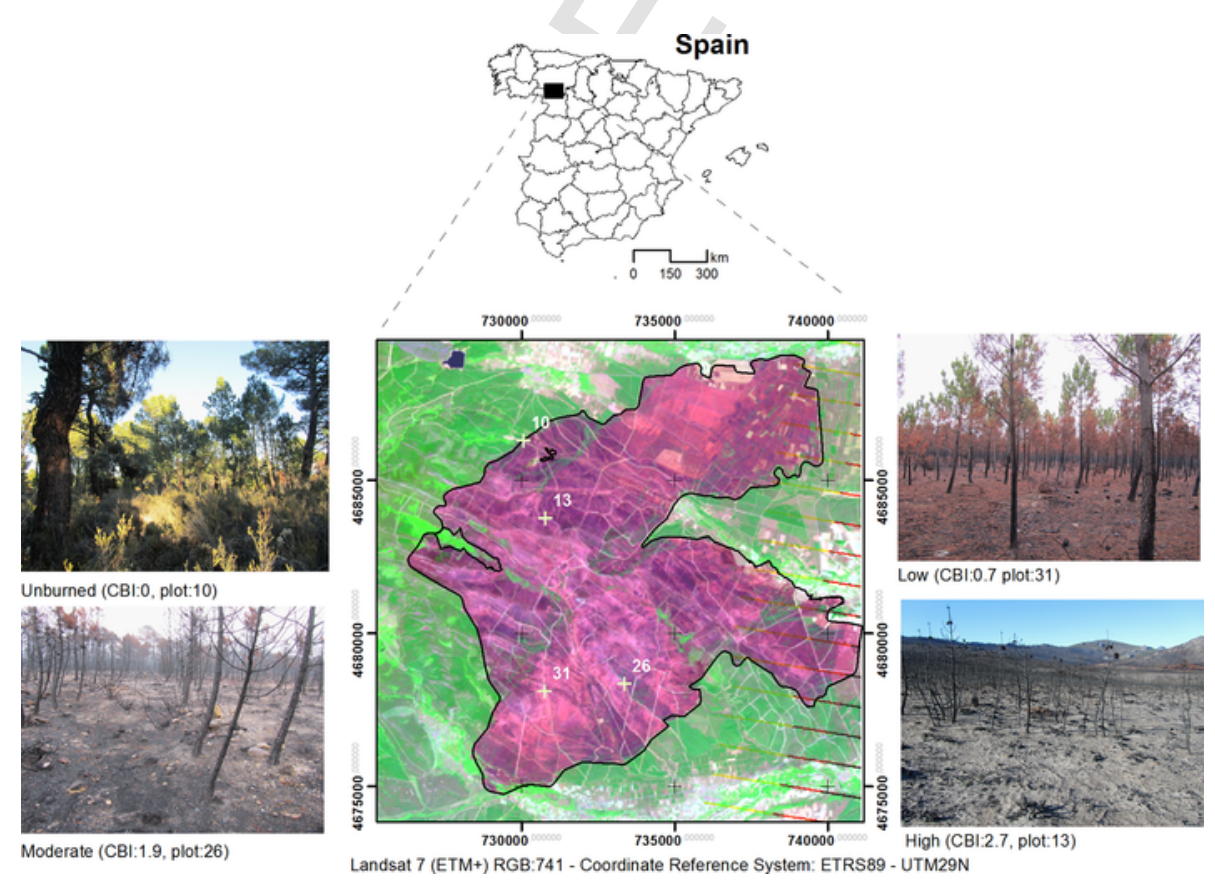

Fig. 1. Location of study area with examples of different burn severity levels by field photograph (adapted from Fig. 2 of Quintano et al., 2015). 
severity (47 plots). Fig. 1 displays some examples of each burn severity level. The relatively high number of high severity plots versus low severity plots (47 vs. 8) is due to the existence of a high intensity fire. The predominant burn severity level was high burn severity, whereas low burn severity was mostly found close to the fire limits and in small humid valleys.

\subsubsection{Remotely sensed data}

Our study was based on a Landsat 7 ETM + scene acquired approximately two weeks after the fire on 6 September 2012. Fortunately, the study area was situated in the zone of the scene not influenced by the malfunction of the scan line corrector (SLC) in May 2003. We downloaded the scene with a L1G level of processing from the US Geological Survey (USGS). A L1G level means that the data product has been radiometrically and geometrically corrected and that the scene has been rotated, aligned and geo-referenced to the UTM map projection.

\subsubsection{Additional data}

Ancillary data included a digital elevation model (DEM), a post-fire digital orthophotograph, the MODIS precipitable water product (MOD 05) and the MODIS Land Surface Temperature and emissivity product (MOD 11). The DEM helped us to topographically normalize the Landsat 7 ETM + image. We used the Advanced Spaceborne Thermal Emission and Reflection Radiometer (ASTER) Global Digital Elevation Model Version 2 (GDEM V2) provided by USGS. The digital orthophotograph assisted us to define the candidate endmember spectra. Specifically we utilized a $0.7 \mathrm{~m}$-pixel digital orthophotograph acquired in 2014 and supplied by the Spanish National Center of Geographic Information (CNIG; http://www.cnig.es/ ) through the Spanish Aerial Orthophotography National Planning (PNOA) agency. Finally, the MOD05 product (precipitable water) enabled us to define the atmospheric water vapor content $(w)$ (see Eq. (2)) and the MOD11 product (LST and Emissivity) allowed us to assess the accuracy of our computed LST Landsat image. Both MODIS products were downloaded from the National Aeronautics and Space Administration (NASA) Earth Observation System Data and Infor mation System (EOSDIS) web interface (http://reverb.echo.nasa.gov/ )

\section{Methods}

Our study is organized into four main stages: 1) pre-processing of the Landsat scene; 2) application of MESMA to reflective Landsat bands; 3) LST calculation from Landsat thermal band; and 4) MLR, to determine the probability of each burn severity level from the MESMA fraction images and LST (see Fig. 2).

\subsection{Pre-processing}

First, the downloaded image was co-registered to the digital orthophoto and DEM. The misregistration error between the Landsat image and the post-fire orthophoto was $<7.5 \mathrm{~m}$ ( 0.25 of a Landsat pixel). Next, the Landsat 7 ETM + scene was subset to the selected forest fire. Specifically latitude/longitude coordinates were: upper left corner, $42^{\circ} 20^{\prime} 38.27^{\prime \prime} \mathrm{N} / 6^{\circ} 16^{\prime} 49.51^{\prime \prime} \mathrm{W}$; and lower right corner $42^{\circ} 13^{\prime} 59.97 \mathrm{~N} / 6^{\circ} 8^{\prime} 28,40^{\prime \prime} \mathrm{W}$. Subsequently, we performed a topographic normalization based on the C-correction algorithm (Teillet et al., 1982). Ten percent of the pixels were randomly selected to compute the $\mathrm{C}$ constant used to correct the image. Next, the topographically normalized image was scaled to radiance values $\left(\mathrm{L}_{\lambda}\right)$ using the method proposed by Chander et al. (2009) who tabulated the updated necessary rescaling factors for the Multispectral Scanner (MSS), Thematic Mapper (TM), Enhanced Thematic Mapper Plus (ETM +) sensors on board of Landsat satellites and Advanced Land Imager (ALI) on board of Earth Observing Mission 1 (EO-1). Finally, the radiance values were converted to surface reflectance $(\rho)$ using the image-based cosine of the solar transmittance (COST) method (Chavez, 1996). The COST method improves upon the simpler image-based Dark Object Subtraction (DOS) technique (Chavez, 1988, 1989) because it corrects the multiplicative transmittance effect. Chavez (1996) stated empirically that the cosine of the solar zenith angle is a good approximation of the atmospheric transmittance along the path from the sun to the ground surface $\left(\tau_{1}\right)$. Additionally, Chavez (1996)

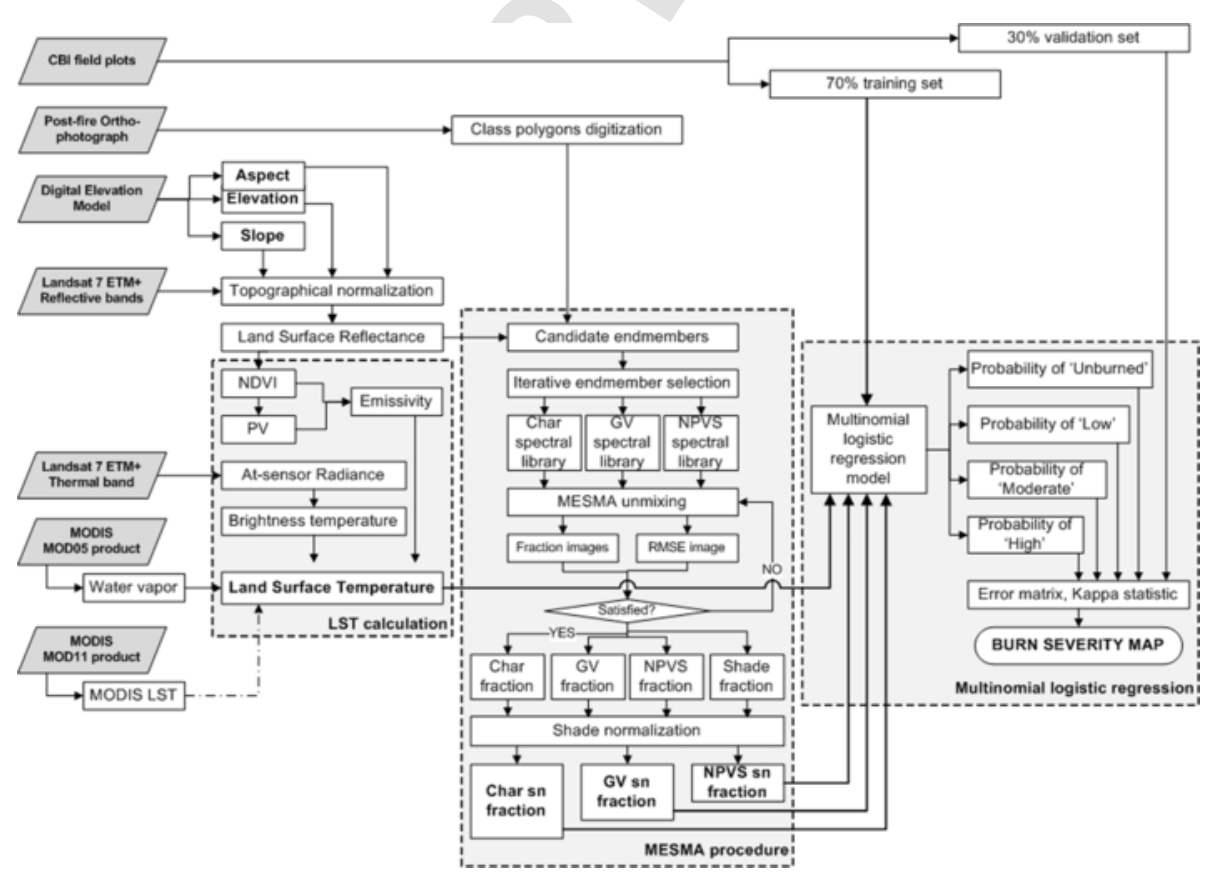

Fig. 2. Flowchart of methodology. 
provided default $\tau_{1}$ values for bands $1-4$. Such values together with the values proposed by Gilabert et al. (1994) for bands 5 and 7, are the recommended values by the Spanish Remote Sensing Planning framework. For that reason, we used them to atmospherically correct the radiance values. All pre-processing calculations were performed on $\mathrm{R}$ development software.

\subsection{MESMA procedure}

Linear SMA, the base for MESMA, assumes that each pixel is constituted by a weighted linear combination of endmembers that represent the whole image, in which the fractional coverage of each endmember within the pixel acts as the weight (Keshava and Mustard, 2002; Quintano et al., 2012; Roberts et al., 1993). In contrast, using MESMA, each pixel maybe unmixed by a different set of endmember spectra (model). In this way, the number of components in which a scene can be spectrally unmixed is not restricted to the quantity of endmembers used. The model selected to unmix each pixel is the one that minimizes the RMSE and meets all fraction and fit constraints (Roberts et al., 1998). An adequate endmember choice is a fundamental stage to success in the unmixing procedure (Tompkins et al., 1997). The endmember spectra should exhibit distinguishable attributes in the scene and be of interest to the user (Quintano et al., 2012). Reference endmembers are taken from spectral libraries whereas image endmembers are defined from the image itself. A disadvantage of using reference spectra is the need of an accurate image correction that is complex and where errors always appear (Drake et al., 1999). By contrast, image endmembers are relatively easy to obtain and they were measured as the same scale as the image data. As done in previous studies (Fernández-Manso et al., 2012; Somers et al., 2012; Youngentob et al., 2011), we formed our spectral library using image endmembers.

Following Dudley et al. (2015) and Roberts et al. (2015), we used georeferenced polygons from high spatial resolution ortophotographs to define the potential endmembers and to form a large spectral library of candidate endmembers. Uniform polygons of just one class were digitized and stored in a shape file. Table 1 indicates the number of polygons used for each class. We used Iterative Endmember Selection (IES, Roth et al., 2012; Schaaf et al., 2011) to reduce the size of the spectral library and to improve MESMA run times. IES is an automated technique that uses an RMSE threshold to identify the endmembers that best model the spectra in a potential spectral library. Initially, accuracy is determined using $\kappa$ statistic (Congalton, 1991) and progressively IES adds or subtracts endmembers to increase the $\kappa$ statistic value. As IES chooses exclusively those endmembers that improve the $\kappa$ statistic, it is possible that endmembers for determined categories are not included in the final endmember library (Roth et al., 2012). Thus, following Roberts et al. (2007), the common spectral shape of the spectra and our knowledge of the study area were considered as well.

Once the final spectral endmembers were selected, they were organized into three spectral libraries (char, green vegetation $(\mathrm{GV})$, and non-photosynthetic vegetation and soil (NPVS)). This grouping produced the highest number of classified pixels after unmixing the image and enabled us to have available a char fraction image representative of burned vegetation. Using the following selection specifications, the behavior of all candidate models for each pixel was examined: -0.05 and 1.05 were defined as minimum and maximum, respectively, allowable fraction values; 0.8 was set as the maximum allowed shade fraction value; and 0.025 was established as the maximum permissible RMSE. In the case of multiple models fulfilling these specifications, the model whose RMSE is the lowest was cho
Table 1

Endmember definition and summary of MESMA procedure.

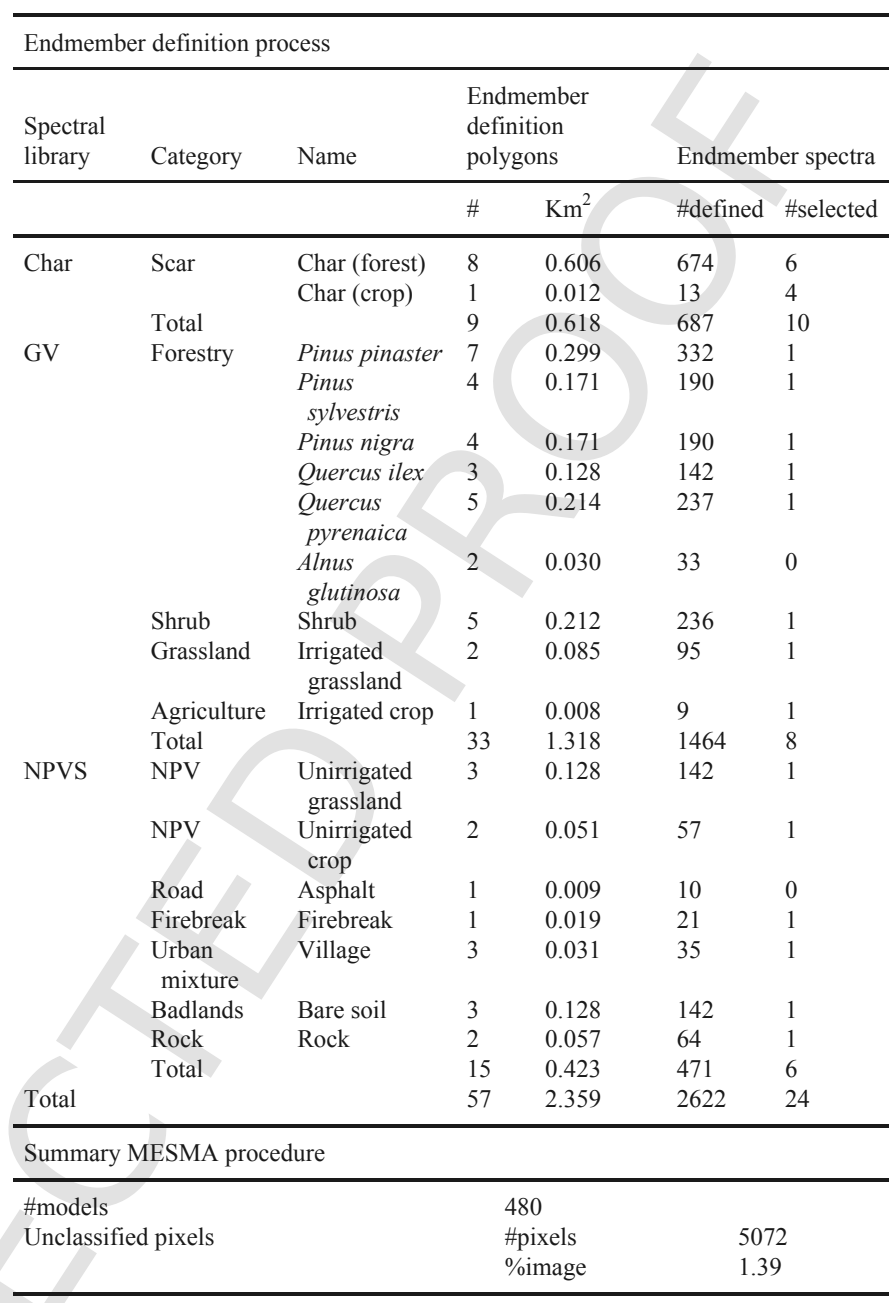

GV: green vegetation; NPV: no-photosynthetic vegetation; NPVS: no-photosynthetic vegetation and soil.

sen. All constraint values were successfully used in previous studies (Dudley et al., 2015; Quintano et al., 2013; Roberts et al., 2012; Roth et al., 2012; Schaaf et al., 2011; Thorp et al., 2013). In addition, we defined a number of classified pixels threshold equal to $95 \%$; meaning that the MESMA fraction images were only definitely accepted if the number of classified pixels of each Landsat image was above $95 \%$. When this condition was not fulfilled, we changed the spectra included in the spectral libraries (number and/or type) and unmixed again the post-fire image.

Finally, the fraction images were shade normalized. Each pixel of char, GV, and NPVS fraction images was divided by the sum of all non-shade fraction images in such pixel. Since the shade endmember was removed, we gained new information on the relative abundance of non-shade endmembers. The Visualization and Image processing for Environmental Research (VIPER) tools software (v1.5 and v2.0) was used in this work to perform all mentioned MESMA procedures.

\subsection{LST calculation}

The $6 \mathrm{~L}$ thermal band was converted to brightness temperature as suggested by Chander et al. (2009). Next, following the single channel algorithm initially proposed by Jiménez-Muñoz and Sobrino 
(2003) and updated by Jiménez-Muñoz et al. (2009) we retrieved LST (Eq. (1)).

$$
\mathrm{LST}=\gamma\left[\frac{1}{\varepsilon}\left(\psi_{1} \mathrm{~L}_{\mathrm{sen}}+\psi_{2}\right)+\psi_{3}\right]+\delta
$$

where at-sensor radiance is represented by $\mathrm{L}_{\text {sen }}$; land surface emissivity by $\varepsilon$; two parameters dependent on the Plank's function by $\gamma$ and $\delta$, respectively, and the so-called atmospheric functions (AFs) by $\psi_{\mathrm{i}}$ with $i=1,2,3$. We assumed that AFs are dependent only on atmospheric water vapor content $(w)$. Thus, we could approximate the AFs by a second-degree polynomial (Eq. (2)).

$$
\Psi=\mathrm{CW}
$$

where the AFs are symbolized by $\Psi ; w$ is incorporated in the equation by $\mathrm{W}$; and different coefficients calculated by simulation are represented by $\mathrm{C}$ (cij, $i=1,2,3, \mathrm{j}=1,2,3)$. Following Jiménez-Muñoz et al. (2009), the Moderate Resolution Imaging Spectroradiometer (MODIS) precipitable water product (MOD 05) enabled us to define the value of $w$. As recommended by the Spanish Remote Sensing Program (PNT) the matrix of coefficients $\mathrm{C}$ was calculated based on the TIRG61 database (Sobrino et al., 1993) that includes 61 atmospheric profiles. We estimated the land surface emissivity $(\varepsilon)$ using the procedure suggested by Sobrino et al. (2008). This methodology is based on NDVI thresholds and calculates $\varepsilon$ from proportion of vegetation cover and red band reflectivity.

Once LST was computed, we checked its accuracy by comparing the obtained LST image to the LST image from the daytime MODIS LST and Emissivity products. The histograms of both LST images were compared to verify that differences in mean and range were insignificant. After validating the Landsat-based LST image, it was re-scaled to [0-1] range (similarly to MESMA fraction images). We denoted the re-scaled LST image by LST_s.

\subsection{Multinomial Logistic Regression}

Before extracting the values of the shade normalized fraction images and LST_s for the field plots, we applied a mean $3 \times 3$ filter to these images. As burn severity is a discrete variable with more than two categories, MLR (Agresti, 2002), an extension of binomial logistic regression (BLR), was selected to relate the burn severity level to the explanatory variables. It describes the relationship between a polytomous or categorical response and one or more explanatory variables (Hosmer et al., 2013), and builds trustworthy predictive models from explanatory variables (continuous or discrete) (Agresti, 2002). MLR does not suppose either normality or linearity or homoscedasticity. Moreover, MLR does not assume any distribution of variable relationships (Osborne, 2014). The MLR probability estimate for each category always varies from 0 to 1 , generating a realistic probability surface. As indicated by Koutsias and Karteris (2000) this model behavior is regarded as an advantage over other statistical methods, in which the probability estimates may fluctuate outside of the interval [0-1]. The probabilistic outputs of MLR are easy to interpret and can act as inputs to hard classifiers (from using a probability threshold to the classical maximum likelihood classifier) (Hogland et al., 2013).

Similar to logistic regression models, in MLR analysis when the dependent variable exhibits a number of categories, one of them is chosen as the reference category. In this way, the probability of membership in the different categories is related to the probability of membership in the reference category (Hosmer et al., 2013). In our study, the high burn severity level was taken as the reference category since it is the most numerous category. Thus, MLR provided us three equations, one for each non-referential category (unburned, low, and moderate burn severity level) to illustrate the relationship among the response and the explanatory variables (Eqs. (3)-(6)). The probability of the reference category is described in Eq. (6).

$$
\begin{aligned}
\mathrm{p}(\mathrm{U}) & =\frac{\exp \left(\mathrm{Z}_{\mathrm{U}}\right)}{1+\exp \left(\mathrm{Z}_{\mathrm{U}}\right)+\exp \left(\mathrm{Z}_{\mathrm{L}}\right)+\exp \left(\mathrm{Z}_{\mathrm{M}}\right)} \\
\mathrm{p}(\mathrm{L}) & =\frac{\exp \left(\mathrm{Z}_{\mathrm{L}}\right)}{1+\exp \left(\mathrm{Z}_{\mathrm{U}}\right)+\exp \left(\mathrm{Z}_{\mathrm{L}}\right)+\exp \left(\mathrm{Z}_{\mathrm{M}}\right)} \\
\mathrm{p}(\mathrm{M}) & =\frac{\exp \left(\mathrm{Z}_{\mathrm{M}}\right)}{1+\exp \left(\mathrm{Z}_{\mathrm{U}}\right)+\exp \left(\mathrm{Z}_{\mathrm{L}}\right)+\exp \left(\mathrm{Z}_{\mathrm{M}}\right)} \\
\mathrm{p}(\mathrm{H}) & =\frac{1}{1+\exp \left(\mathrm{Z}_{\mathrm{U}}\right)+\exp \left(\mathrm{Z}_{\mathrm{L}}\right)+\exp \left(\mathrm{Z}_{\mathrm{M}}\right)} \\
& =1+\mathrm{p}(\mathrm{U})-\mathrm{p}(\mathrm{L})-\mathrm{p}(\mathrm{M})
\end{aligned}
$$

where, $\mathrm{U}, \mathrm{L}, \mathrm{M}$, and $\mathrm{H}$ represent unburned, low, moderate, and high burn severity level, respectively; and $Z_{i}(i=U, L, M, H)$ is represented in Eq. (7).

$$
\mathrm{Z}_{\mathrm{i}}=\beta_{0 \mathrm{i}}+\sum_{\mathrm{j}=1}^{\mathrm{k}} \beta_{\mathrm{ji}} \mathrm{X}_{\mathrm{j}}
$$

where, the regression coefficients are represented by $\beta_{\mathrm{j}}(\mathrm{j}=0 \ldots \mathrm{k}$ : number of independent variables), and the independent variables by $X_{j}$ $(\mathrm{j}=1 \ldots \mathrm{k})$.

The whole data set was randomly split into two groups, the training set ( $70 \%$ of CBI plots) and the validation set (30\% of CBI plots). The samples were well balanced with respect to the proportion of plots with unburned, low, moderate and high burn severity levels. Additionally, as suggested by Hosmer et al. (2013) we considered a minimum of 10 cases per independent variable. As in other studies (Montealegre et al., 2014; Vasques et al., 2015; Waser et al., 2014) we applied the forward stepwise method to the training dataset to choose the independent variables. The starting point of the forward stepwise method is the model determined by the forward entry method: a model where only the most significant variables are included (the variables without statistically significant contribution are omitted). From this initial model, the forward stepwise method alternates between backward suppression on the stepwise variables in the model and forward entry on the variables omitted. To assess the goodness of models and the significance of variables the log likelihood $(-2 \mathrm{LL})$ statistic and the likelihood ratio (LR) Chi-Square test were used. Cox and Snell, Nagelkerke and McFadde pseudo- $\mathrm{R}^{2}$ tests were also considered.

Once the model was selected, the intercept and the weights of the variables incorporated into it were used to calculate the probability of each burn severity class $(\mathrm{p}(\mathrm{U}), \mathrm{p}(\mathrm{L}), \mathrm{p}(\mathrm{M})$, and $\mathrm{p}(\mathrm{H}))$. The probability images were then combined, selecting for each pixel the burn severity class with the highest probability. The burn severity estimate was val 
idated using the $\mathrm{CBI}$ validation plots using an error matrix and through the $\kappa$ statistic (Congalton, 1991). Overall accuracy (OA) as well as producer accuracy (PA) and user accuracy (UA) of each class were also computed.

\section{Results}

The set of geo-referenced polygons defined over the post-fire ortho-photographs enabled us to find the spectra of each class (Table 1). We used three spectral libraries: char, GV and NPVS. Table 1 provides more information about the endmember selection process. The char spectral library was defined by 9 polygons digitized inside the fire scar. These polygons included 687 endmember spectra. The GV spectral library was generated from 33 polygons grouped in to four categories: forest, shrub, grassland and agriculture. In this way, we obtained 1464 candidate endmembers, representing Pinus pinaster, $\mathrm{Pi}$ nus sylvestris, Pinus nigra, Quercus ilex, Quercus pyrenaica, Alnus glutinosa, shrub, grassland and crops. Finally, we grouped NPV and soil into one spectral library, NPVS. Fifty polygons were digitized including NPV, roads, firebreaks, urban mixtures, badlands and rocks, which allowed us to obtain 471 potential endmember spectra. Using the IES algorithm and considering the typical spectral profile of the endmember spectra and our knowledge of the study area, the number of endmember spectra that we finally selected included 10 char spectra, 8 GV spectra and 6 NPVS spectra (see Fig. 3 for an example of the selected endmember spectra from each category). A total of 480 models $(10 * 8 * 6=480)$ were run on each pixel using MESMA, classifying $98.61 \%$ of the Landsat 7 ETM + image.

Next, fraction images were shade normalized. In Fig. 4 we can visually notice distinct burned and unburned areas in the shade normalized char and GV fraction images. Furthermore it is possible to differentiate some variations inside the fire scar that we presume are related to burn severity. Fig. 4 (right lower corner) also displays the post-fire LST image. Similarly to shade normalized fraction images, LST allowed us to observe notable spatial variation in temperature between burned and unburned areas, with unburned areas cooler. In addition, we observed temperature variations inside of burn limit that presumably reflect differences in burn severity. Thus, the visual analysis suggests that both MESMA fraction images and LST are sensitive to burn severity levels.

Differentiating three levels of burn severity from satellite data is not always possible (Miller and Thode, 2007; Quintano et al., 2015; Tanase et al., 2011). For this reason, we applied MLR to the training set of the work database, considering both three and two burn severity levels. When we took into account just two burn severity levels, the low and moderate burn severity classes were merged. Table 2 shows the results of the forward stepwise method applied to the training set to choose the explanatory variables included in the model. In both cases (two and three burn severity levels) only two independent variables were selected: shade normalized char fraction image and LST_s as they were the only significant ones.

The most relevant parameters of these MLR models are displayed in Table 3. The - 2LL was lower and LR Chi-Square was higher when only two burn severity levels were taken into account indicating a better statistically significant agreement $(\mathrm{p} \leq 0.001)$ (Hosmer et al., 2013). Like linear regression, the pseudo-R-squared values roughly display how much variation the model explains. In our case, the three pseudo R-square statistics are higher when two instead of three burn severity levels are considered. Similarly, the OA of the burn severity estimates within the training set when two burn severity levels were considered was higher than the OA if we take into account three burn severity levels. We found both models highly significant (Significance $<0.000)$. The coefficient or parameter estimates of both independent variables are negative and significant, suggesting that a reduction in either shade normalized char fraction image or LST_s determines an increment in burn severity.

To highlight the contribution of LST to the MLR model, the forward stepwise method was applied again to the training set, excluding LST s as independent variable. In this case, only the shade normalized char fraction image was included in the MLR model for both two and three burn severity levels. Table 3 also shows the summary of MLR parameters when only the shade normalized char fraction image was used as an explanatory variable. The comparison of MLR parameters when LST_s is or is not included as an explanatory variable, illustrates the contribution of LST s to the model. In both cases (two and three burn severity levels) the $\kappa$ statistic increased when LST_s was included (from 0.59 to 0.79 , and from 0.55 to 0.66 , respectively).

From the accuracy analysis shown in Table 3, the MLR model with two explanatory variables and two burn severity levels was selected to obtain the final burn severity probabilities. A $\kappa$ statistic of 0.66 (three burn severity levels) was considered insufficient. Table 4 displays the accuracy measures of the selected MLR model for the training and validation set. Very similar values were obtained $(\mathrm{OA} \approx 85 \%$ and $\kappa$ statistic $\approx 0.78$ ). Both error matrices showed some confusion between low-moderate and high burn severity classes. The validation error matrix also indicated some confusion between low-moderate burn severity and unburned classes.

Once validated, the parameter estimates shown in Table 3 were included in Eqs. (5)-(9) to calculate the probabilities of unburned class, low-moderate burn severity class and high burn severity class. These predicted probabilities are plotted in Fig. 5. Fig. 5, upper left, shows the probability of the unburned class inside the fire scar. There are some white spots (high probability of unburned) inside the fire perimeter. Fig. 5, middle left, displays the probability of low-moderate burn severity class. Finally, Fig. 5, lower left, displays the proba
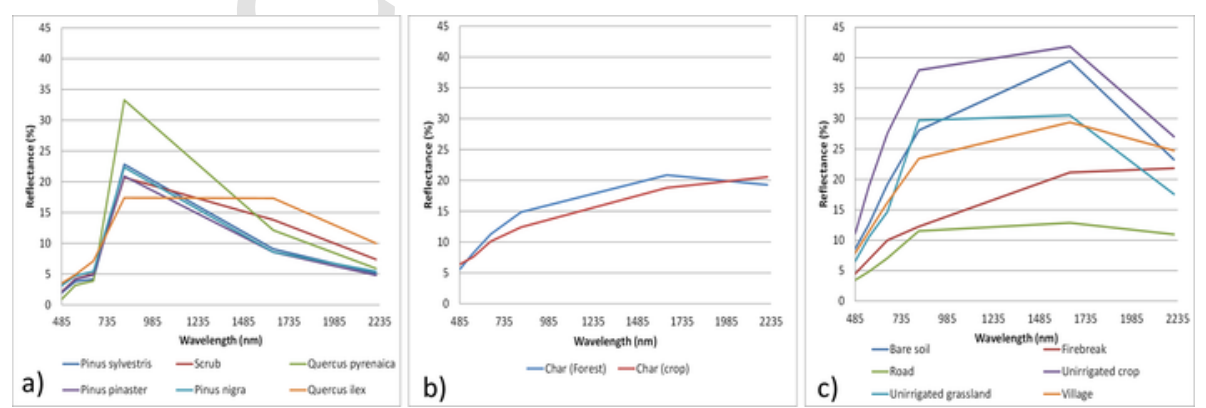

Fig. 3. Example spectra from the final spectral libraries. a) Green vegetation spectral library; b) char spectral library; c) non-photosynthetic vegetation and soil spectral library. 
a)

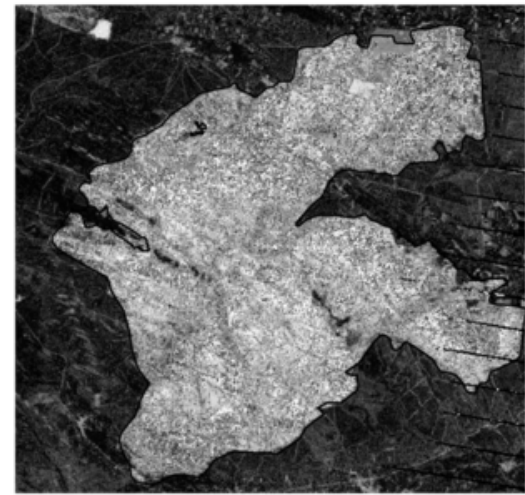

b)

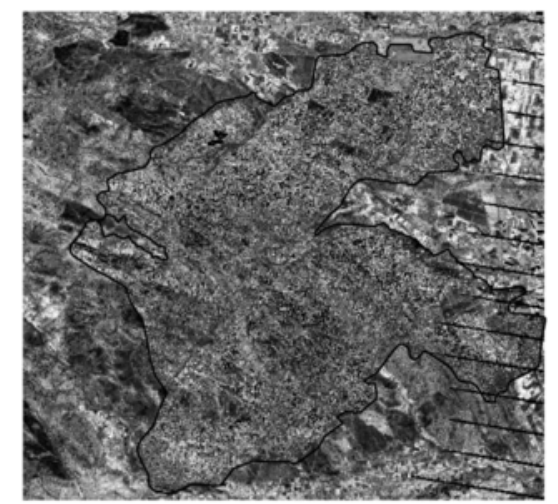

Enmembers legend

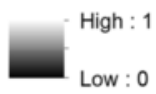

Reference Coordinate System: ETR89 -UTM29N

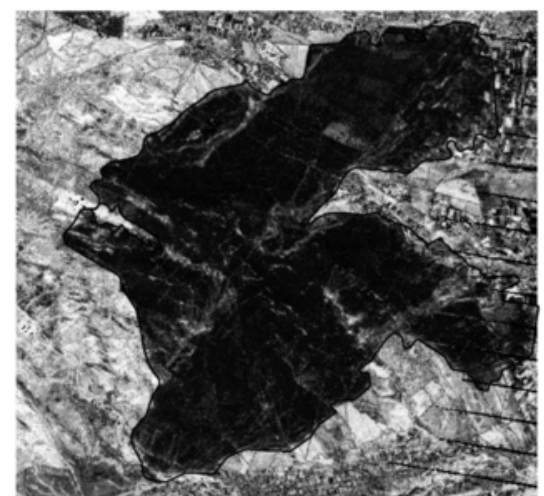

c)

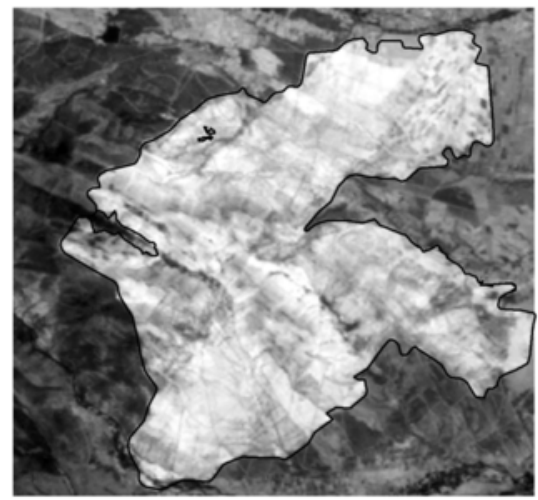

LST legend (K)

High : 324,953

Low : 292,196

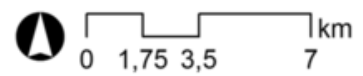

Fig. 4. Shade normalized fraction images and LST. a) shade normalized char fraction; b) shade normalized NPVS fraction; c) shade normalized GV fraction; d) LST image.

Table 2

Selection of the explanatory variables used in the Multinomial Logistic Regression (stepwise method).

\begin{tabular}{|c|c|c|c|}
\hline \multirow[t]{2}{*}{ Effect } & \multirow[t]{2}{*}{$-2 \log$ likelihood of reduced model } & \multicolumn{2}{|c|}{ Likelihood ratio tests } \\
\hline & & Chi-Square & Sig. \\
\hline \multicolumn{4}{|c|}{ Two burn severity levels } \\
\hline Intercept & 102.394 & 31.535 & 0.000 \\
\hline LST_s ${ }^{\mathrm{a}}$ & 93.672 & 22.814 & 0.000 \\
\hline Char_sn ${ }^{\mathrm{a}}$ & 84.453 & 13.594 & 0.001 \\
\hline GV_sn & 71.214 & 0355 & 0.837 \\
\hline NPV̄S_sn & 70.883 & 0.024 & 0.988 \\
\hline \multicolumn{4}{|c|}{ Three burn severity levels } \\
\hline Intercept & 129.311 & 27.437 & 0.000 \\
\hline LST_s ${ }^{\mathrm{a}}$ & 129.679 & 27.805 & 0.000 \\
\hline Char_sn ${ }^{\mathrm{a}}$ & 115.560 & 13.687 & 0.003 \\
\hline GV_sn & 107.043 & 5.170 & 0.160 \\
\hline NPV̄S_sn & 103.405 & 1.531 & 0.675 \\
\hline
\end{tabular}

LST_s: land surface temperature scaled to $[0,1]$ range; Char_sn: shade normalized char fraction image; GV_sn: shade normalized green vegetation fraction image; NPVS_sn: shade normalized non-photosyntetic vegetation and soil fraction image.

a Explanatory variables selected by the forward stepwise method. The chi-square statistic is the difference in -2 log-likelihoods between the final model and a reduced model. The reduced model is formed by omitting an effect from the final model. The null hypothesis is that all parameters of that effect are 0 .

bility of high burn severity class. Most of this image appears in white tones indicating a high proportion of high burn severity class as really occurred. The categorical maps of burn severity are valuable for for est management plans. For that reason, Fig. 5, right, shows the burn severity estimate obtained by selecting the class with the highest probability in each pixel. It can be noticed that most of the area was classified in at the high burn severity level.

\section{Discussion}

A total of $98.61 \%$ of the image was classified by MESMA using three spectral libraries: char, GV, and NPVS. This high value could not be obtained without an adequate endmember selection. As Maselli (1998) summarized, a satisfactory set of endmembers must meet several conditions: linear independency, spectral representativity and spatial generality. Many previous MESMA based studies (Franke et al., 2009; Quintano et al., 2013; Roberts et al., 2012; Youngentob et al., 2011) used indices such as: Count based Endmember Selection (CoB, Roberts et al., 2003), Endmember Average RMSE (root mean squared error) (EAR, Dennison and Roberts, 2003) and Minimum Average Spectral Angle (MASA, Dennison et al., 2004) to define the final spectral libraries. In this study, IES was used to find the best subset of endmembers. IES is a relatively new method to reduce the size of the spectral library by selecting only the endmember spectra that increase $\kappa$ statistic (Roth et al., 2012). This approach resulted in the most favorable selection of endmembers. Consequently, an accurate burn severity estimate could be obtained from the fraction images.

Fig. 6 shows the combined contribution of the potential explanatory variables from a graphical perspective. A four-axis chart, one for 
Table 3

Comparison of MLR models considering two and three burn severity levels and including shade normalized char fraction image and land surface temperature scaled to $[0,1]$ or just shade normalized char fraction image.

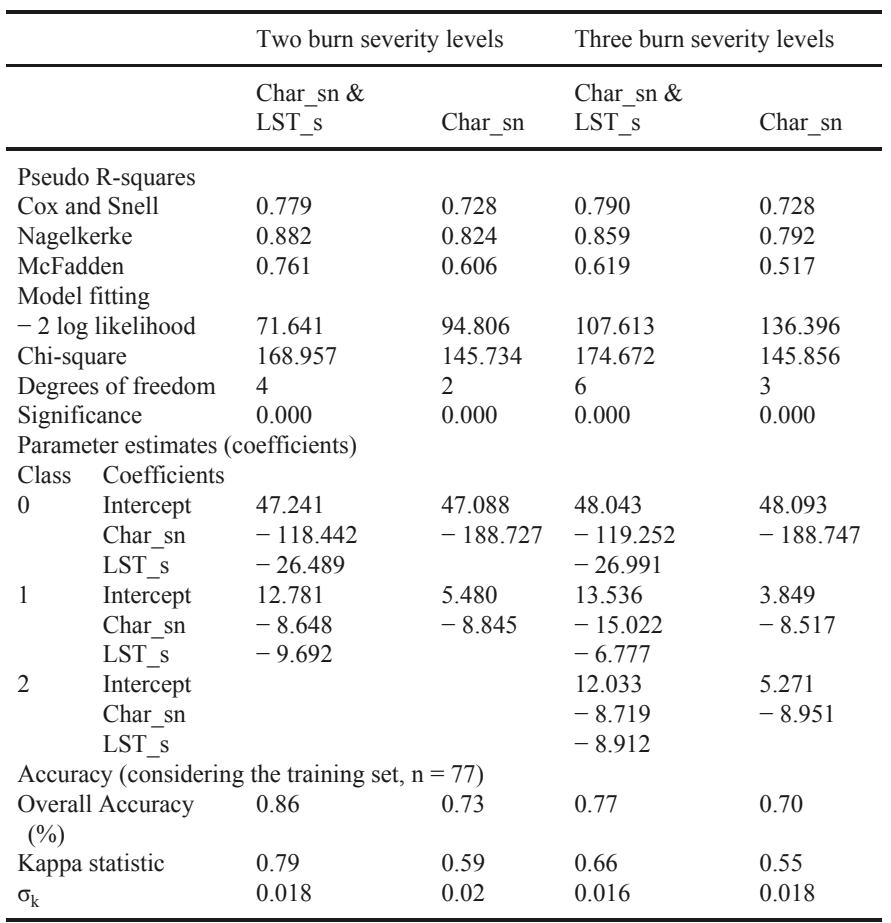

Char_sn: shade normalized char fraction image; LST_s: land surface temperature scaled to $[0,1]$ range; class 0 : unburned class; class 1 : low-moderate class when three burn severity levels were considered, or low class when four burn severity levels were considered; class 2: moderate burn severity level; the high burn severity level is the reference class.

each variable (shade normalized char, GV and NPVS, and LST s) is shown for the unburned plots (left), for the low-moderate burn severity level plots (center), and for the high level (right). From these plots it is possible to observe the characteristics of the different burn sever ity categories. Unburned plots display a high GV value (near 1), near zero char fraction, and the lowest soil fraction and LST values. In contrast, high burn severity plots (Fig. 6 right) display minimal GV values, maximum values of char fraction and the highest values of soil fraction and LST. The low-moderate burn-severity plots have intermediate values between unburned and high burn severity level, displaying relatively high values of char fraction and LST_s, and low-medium values of GV. These results agree with the characterization of the unburned, low, moderate and high burn severity plots regarding fraction images made by previous studies (Fernández-Manso et al., 2009; Quintano et al., 2013).

In our study, MLR helped to identify which among the shade normalized MESMA fraction images, and LST_s was more important in differentiating burn severity levels. MLR identified the shade normalized char fraction as the most significant explanatory variable for burn severity. This fact agrees with a small number of previous studies that highlighted the potential of char fraction as indicator of burn severity (Fernández-Manso et al., 2009; Hudak et al., 2007; Lentile et al., 2009; Smith et al., 2005; Sunderman and Weisberg, 2011; Veraverbeke and Hook, 2013; Veraverbeke et al., 2014). Most of the previous studies, however, used SMA fraction images. The last two, however, used MESMA-based fractions. Veraverbeke and Hook (2013) defined the quotient between the char fraction (as an indicator of the combusted material) and the sum of char, GV and NPV fractions (as an indicator of all combustible materials) and showed its correlation with burn severity (GeoCBI, de Santis and Chuvieco, 2009) $\left(\mathrm{R}^{2}=0.66\right)$ in eastern Arizona (USA). Veraverbeke et al. (2014) showed that the ratio between combusted and combustible material (from MESMA fractions) was strong correlated to GeoCBI $\left(\mathrm{R}^{2}=0.86\right)$ in the Canyon Fire (California, USA). All of the previous studies except Veraverbeke et al. (2014) were based on multispectral Landsat data. Veraverbeke et al. (2014), however, used AVIRIS imagery.

The second explanatory variable identified by MLR that significantly contributed to model burn severity was LST_s. Other authors have also shown that there is a relationship between thermal data and burn severity. Quintano et al. (2015) concluded that, immediately after fire, LST and CBI (measuring burn severity) are significantly re

Table 4

Error matrices (training and validating) and summary of accuracy parameters.

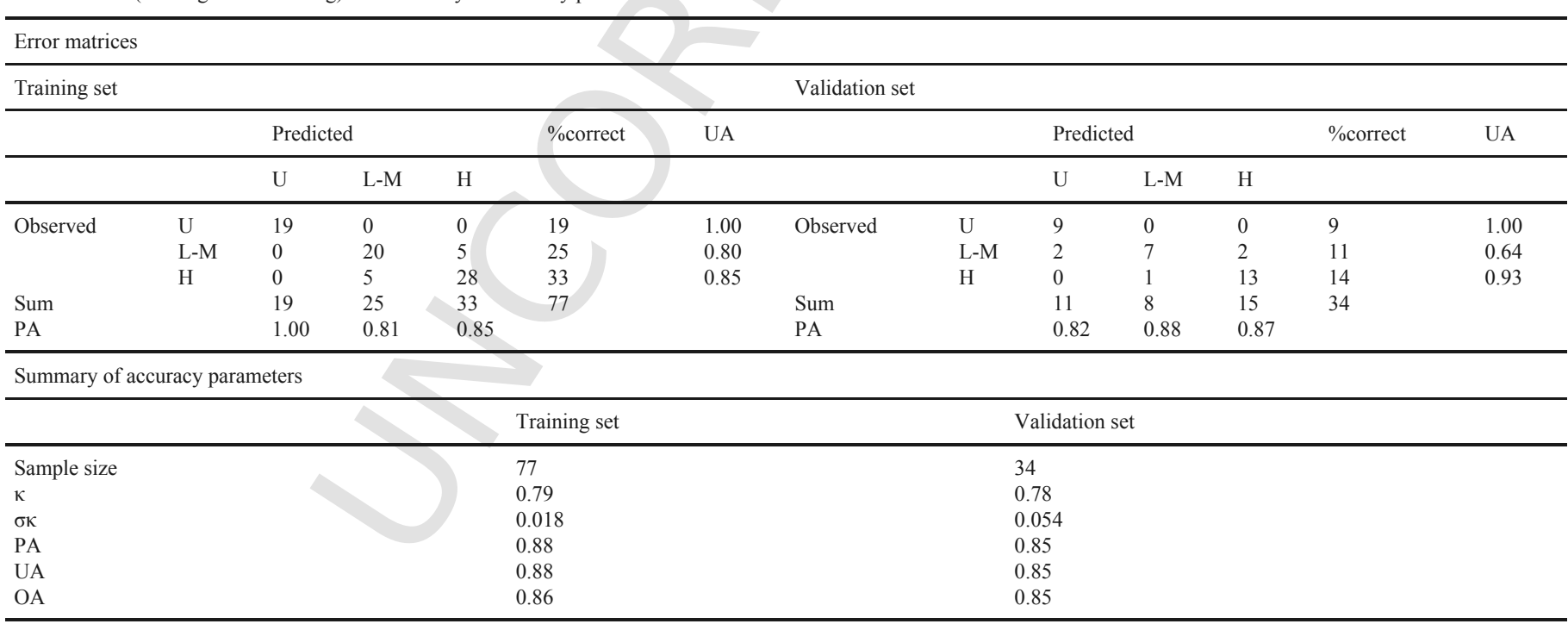

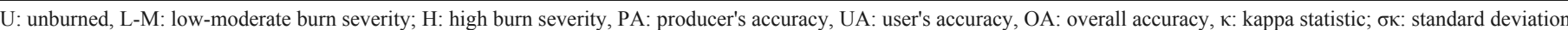
of kappa statistic. 

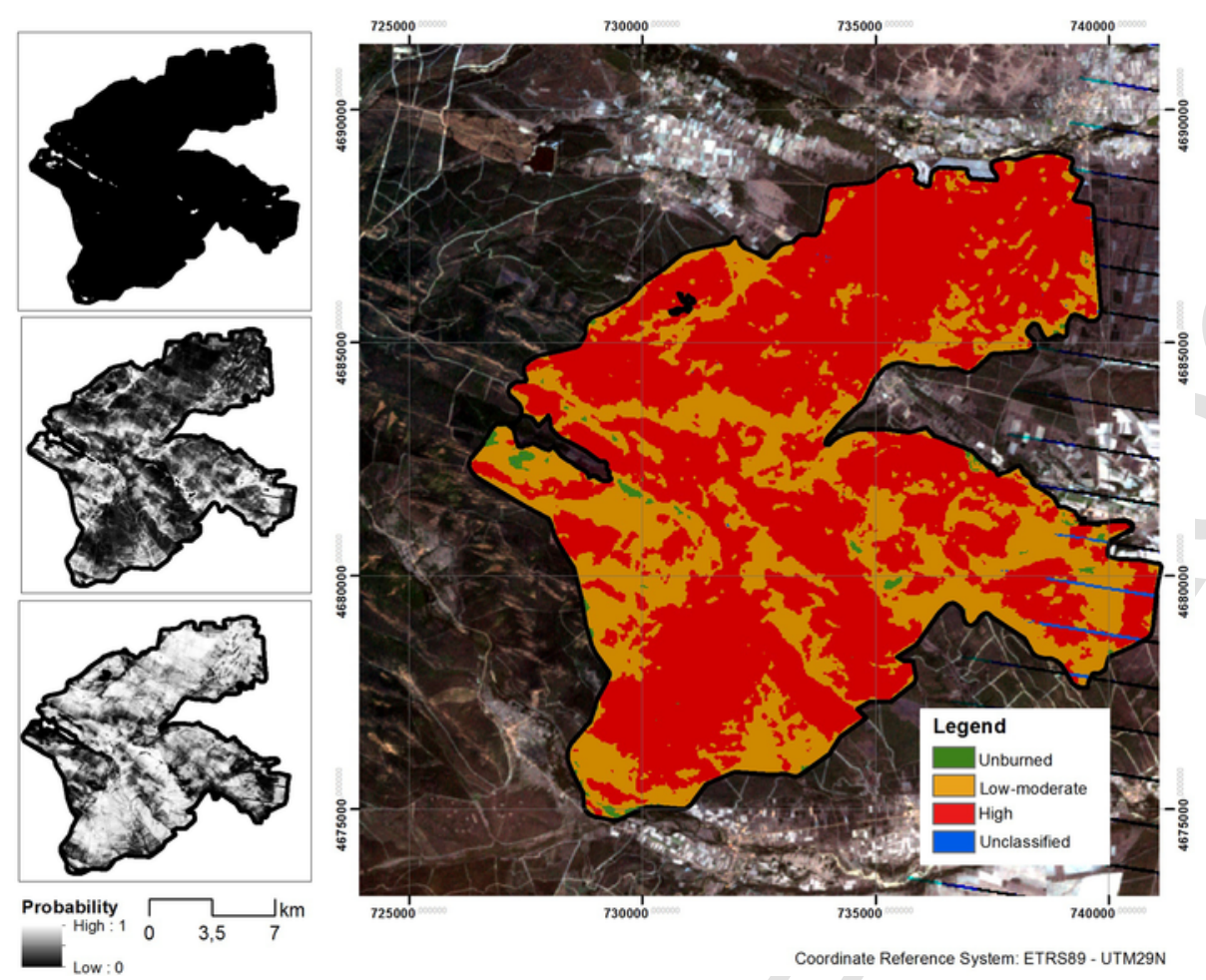

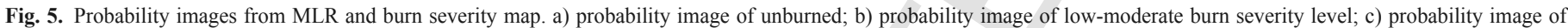
high burn severity level; d) burn severity map.

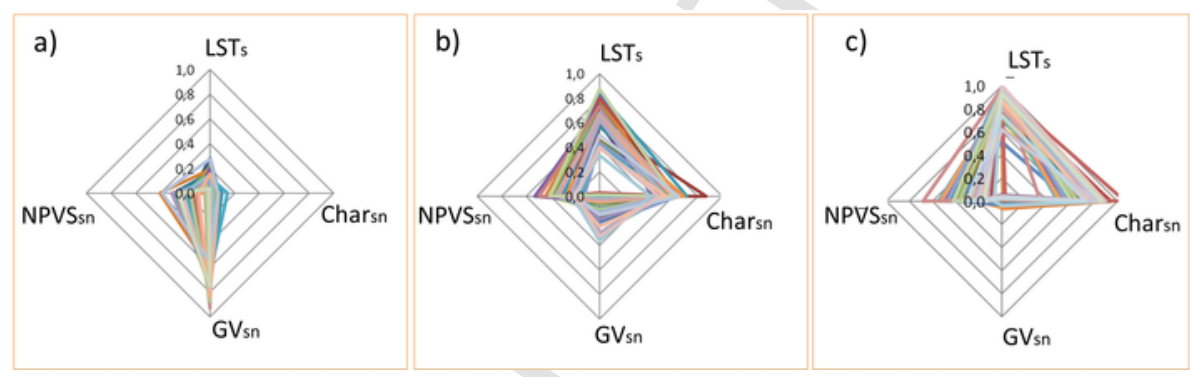

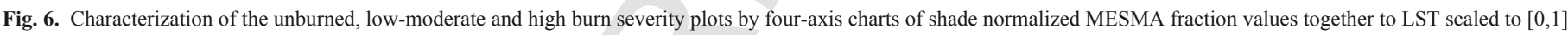
range value. a) unburned; b) low-moderate burn severity level; c) high burn severity level.

lated $\left(\mathrm{R}_{\text {adj }}^{2}=0.84\right)$, that this statistical relation weakens during fall-winter $\left(\mathrm{R}_{\text {adj }}^{2}=0.46\right)$ and strengthens again during the following summer $\left(\mathrm{R}^{2}\right.$ adj $=0.84$, again). They also found that immediately following a fire, LST enabled them to distinguish two burn severity levels with statistical significance (average LST value of unburned $=303.7 \mathrm{~K}$; of low-moderate $=316.2 \mathrm{~K}$; of high $=319 \mathrm{~K}$ ). In their study about post-fire assessments, Veraverbeke et al. (2012b) stated that estimates of char, NPV and substrate based on MESMA fractions from a combination of visible to shortwave infrared (VSWIR) and mid to thermal infrared (MTIR) data were 5-7\% more accurate, than estimates from only VSWIR data. Roberts et al. (2012) reached a similar conclusion when working in urban environments. They found TIR data complemented VSWIR data and vice versa, as the confusion among classes in one spectral region was corrected by the other spectral region.

From these two explanatory variables, MLR provided us three probability images: unburned, low-moderate burn severity level and high level. These probability images have physical meaning, are easy to interpret, and can be used to generate a wide variety of maps iden tifying class locations that are tailored to specific questions, which represents one advantage of MLR (Hogland et al., 2013). The use of fraction images also eases the interpretation of the MLR model since they represent the abundance of each endmember within the pixel. The straight connection between field measures and remotely sensed variables is an important advantage of the unmixing procedure (Morgan et al., 2014; Veraverbeke and Hook, 2013). The combination of MESMA and MLR gave a physical meaning to the whole modeling process, what eased its understanding.

Finally, our burn severity map from the probability images was independently validated obtaining a $\kappa$ statistic of 0.79 when two burn severity levels were considered and 0.66 when three burn severity levels were considered. To compare the accuracy of our burn severity map to the accuracy of burn severity maps obtained by other authors, we used the Cansler and McKenzie (2012) summary of the classification results of studies based on $\mathrm{dNBR}$ or RdNBR and validated with CBI in coniferous forest in North America. From this summary, considering three burn severity levels, $\kappa$ statistic ranged from 0.37 (Soverel et al., 2010) to 0.62 (Cocke et al., 2005). Thus, our result 
$(\kappa=0.66)$ was slightly higher than the highest result. Additionally, to assess the contribution of MESMA fractions and LST as explanatory variables, we obtained the burn severity level probability images from MLR using post-fire NBR as unique explanatory variable. Table 5 shows a summary of the obtained pseudo R-squares and accuracy measures considering two and three burn severity levels. In both cases, $\kappa$ statistic values were similar and lower than $\kappa$ statistic values obtained from the unitemporal proposed method based on MESMA fractions and LST. The synergy between MESMA char fraction and LST found in our study (reflective and thermal bands of Landsat 7 ETM + data) indicates the high potential of the new sensors onboard Landsat 8 (specifically, Operational Land Imager, OLI, and Thermal Infrared Sensor TIRS) and of the Hyperspectral Infrared Imager (HyspIRI) that will combine VSWIR-MTIR imagery at pixel sizes smaller than $100 \mathrm{~m}$.

From the burn severity map of Fig. 5 we observe that most of the burned area was affected by a high burn severity level, a fact that is greatly related to the fire characteristics. The fire burned through a continuous forest mass of $P$. pinaster ( $8183 \mathrm{ha}$ ) and areas recently reforested (1095.17 ha). Only small valleys inside the fire perimeter displayed low burn severity level or unburned level. These islands with lower burn severity were due to three factors: 1.-The areas were located at the bottom of the valley and perpendicularly oriented to the fire propagation axis (SW-NE). For this reason, the fire pattern was against the slope. Thus it had a flame with lower intensity and lower propagation speed. 2.-Valley bottoms are places with higher capability for water retention. For that reason, it is highly probable that the water content of vegetation in these islands was higher than the water content of vegetation in other areas. 3.-The vegetation of these islands was less flammable (Quercus pyrenaica Willd., Pteridium aquilinum L., Cytisus multiflorus L., Cytisus scoparious L.).

The study area is characterized by rugged terrain with $>1000 \mathrm{~m}$ elevation range and strong topographic effects on insolation, water availability and vegetation type and cover density. This environmental heterogeneity can be expected to complicate burn severity mapping. Further complications and confusion may result from the fact that burn severity patterns are constrained by pre-fire vegetation and fuel load patterns. However, the use of MESMA fractions minimized the topographic shadowing effect (shade fraction image) and took into account the variability of vegetation type (GV fraction image), what helped to obtain an accurate burn severity estimate. As MLR showed, LST complemented the char fraction image by adding infor

Table 5

Pseudo R-Squares and accuracy measures of MLR models considering two and three burn severity levels and using as explanatory variable post-fire NBR

\begin{tabular}{|c|c|c|c|c|c|c|}
\hline & \multicolumn{3}{|c|}{ Pseudo R-squares } & \multicolumn{3}{|c|}{$\begin{array}{l}\text { Accuracy (considering the } \\
\text { training set, } \mathrm{n}=77 \text { ) }\end{array}$} \\
\hline & $\begin{array}{l}\text { Cox and } \\
\text { Snell }\end{array}$ & Nagelkerke & McFadden & $\mathrm{OA}$ & $\kappa$ & $\sigma_{\mathrm{k}}$ \\
\hline \multicolumn{7}{|l|}{ NBR } \\
\hline $\begin{array}{l}\text { Two burn } \\
\text { severity levels }\end{array}$ & 0.573 & 0.634 & 0.431 & 0.67 & 0.49 & 0.029 \\
\hline $\begin{array}{l}\text { Three burn } \\
\text { severity levels }\end{array}$ & 0.483 & 0.522 & 0.362 & 0.60 & 0.45 & 0.016 \\
\hline \multicolumn{7}{|c|}{ Char_sn \& LST_s ${ }^{\mathrm{a}}$} \\
\hline $\begin{array}{l}\text { Two burn } \\
\text { severity levels }\end{array}$ & 0.779 & 0.882 & 0.761 & 0.86 & 0.79 & 0.018 \\
\hline $\begin{array}{l}\text { Three burn } \\
\text { severity levels }\end{array}$ & 0.790 & 0.859 & 0.619 & 0.77 & 0.66 & 0.016 \\
\hline
\end{tabular}

${ }^{\text {a }}$ Pseudo R-squares and accuracy measures of MLR models using as explanatory variables shade normalized char fraction image and land surface temperature scaled to $[0,1]$ was included as well to ease the comparison. mation of statistical significance that helped to increase the accuracy of burn severity estimation. A single channel algorithm (proposed by Jiménez-Muñoz and Sobrino, 2003, and updated by Jiménez-Muñoz et al., 2009) was used to compute LST and emissivity was estimated using NDVI. We did not analyze the potential differences of using this algorithm vs., for instance, the mono-window algorithm developed by Qin et al. (2001), or calculating the emissivity by the classification method. However, we did compare MODIS LST (which does not use NDVI) to Landsat LST, and the temperatures were comparable.

Summarizing, the added value of our method can be deduced from the following reasons: 1.-It is a unitemporal method. Thus, we avoided questions relatives to the selection of pre-fire image (no clouds, same phenology, a year before...) and reduced the need of very accurate and precise image correction algorithms; 2.-It is based on MESMA fraction images instead of widely used spectral indices. Consequently, burned vegetation was represented more accurately as we used all reflectance bands information (instead of just information from two spectral bands) and the influence of background effect of soil was reduced. MESMA maximizes the image information by using multiple endmember spectra combined in multiple different models; 3.-It is based as well on thermal information (specifically LST) that has recently been shown to vary with burn severity. Thus, the proposed method may maximize the synergies between Operational Land Imager (OLI) data and Thermal Infrared Sensor (TIRS) data both onboard of Landsat 8 (reflective and thermal); and 4.-It is a simple process, once familiarized with it.

The burn severity mapping method proposed in this study could be readily applied to other ecosystems (Mediterranean and non-Mediterranean). A careful selection of candidate endmembers from the image would make MESMA fractions adaptable to most ecosystems. Regarding LST, the generalized single-channel algorithm used in this study requires minimum input data (only one atmospheric parameter, w). Thus, LST could be computed for these ecosystems without any modification except the value of w. Finally, MLR is a statistical procedure that does not require any specific parameter to characterize the ecosystem to be analyzed. Furthermore, the proposed method could successfully work using satellite data acquired from other systems than Landsat, such as Sentinel, and be readily adapted to use reference endmembers from a spectral library (MESMA procedure) or any other method to compute LST.

\section{Conclusion}

Although reflective spectral indexes are frequently utilized to map burn severity, there is an absence of a definitive method in Mediterranean countries. We validated a unitemporal method that takes advantage of both reflective and thermal spectral bands of Landsat 7 ETM + data and accurately mapped burn severity. Three different levels of burn severity (low, moderate and high) were ground measured by CBI in 111 field plots. MLR was applied to MESMA fractions and LST for accurate burn severity mapping at the regional scale. The obtained burn severity map was validated by means of error matrix, $\kappa$ statistic, and PA, UA and OA values $(30 \%$ of CBI plots acted as validation set). Our results confirmed the high correlation between char fraction image and CBI values (specific objective 1). OA of burn severity map from MESMA char fraction was $73 \%$ when three burn severity levels and 70\% for four burn severity levels (specific objective 3 ). In addition, we showed that the inclusion of LST in the MLR model enabled us to increase the OA to $86 \%$ for three severity levels and to $77 \%$ for four severity levels (specific objective 2). A fundamental factor that enabled us to obtain a high accuracy 
burn severity map was a careful and methodical choice of endmembers representing all land covers under study. In particular, IES helped us identify an optimal selection of the final endmembers that we organized in three spectral libraries (Char, GV, and NPVS).

Our study demonstrates the validity of combining MESMA fraction images and LST from Landsat data to map burn severity accurately in Mediterranean countries. Although we studied a large fire in a Mediterranean $P$. pinaster ecosystem, we are convinced the proposed method could be applied to other Mediterranean and non-Mediterranean ecosystems as long as candidate endmembers are carefully defined. The MESMA-LST based methodology we proposed may contribute to improved interpretation of patterns of burn severity, and to plan improved post-fire management strategies.

\section{Acknowledgments}

The research work was financially supported by the Spanish Ministry of Economy and Competitiveness, and the European Regional Development Fund (ERDF) in the frame of the GES-FIRE project "Multi-scale tools for the post-fire management of fire prone ecosystems in the context of global change" (AGL201348189-C2-1-R). The first author was supported as research visitor at VIPER Lab. (University of California, Santa Barbara) by a Spanish Education Ministry grant (Salvador de Madariaga program, code PRX14/00160). We thank the anonymous reviewers and the editor for their comments, which significantly improved the content of this article.

\section{References}

Adams, J.B., Smith, M.O., Johnson, P.E., 1993. Imaging spectroscopy: Interpretation based on spectral mixture analysis. In: Pieters, C.M., Englert, P.A.J. (Eds.), Remote Geochemical Analysis: Elemental and Mineralogical Composition. Cambridge University Press, Cambridge, England, pp. 145-164.

Agresti, A., 2002. Categorical Data Analysis. Wiley-Interscience, Hoboken, New Jersey, 710.

Alberdi, I., Condés, S., Martínez, J., Martínez, S., de Toda, S., Sánchez, G., Pérez, F., Villanueva, J.A., Vallejo, R., 2010. Spanish national forest inventory. In: Tomppo, E., Gschwantner, T., Lawrence, M., McRoberts, R.E. (Eds.), National Forest Inventories. Pathways for Common Reporting. Springer, pp. 527-540.

Arnett, J.T.T.R., Coops, N.C., Daniels, L.D., Falls, R.W., 2015. Detecting forest damage after a low-severity fire using remote sensing at multiple scales. Int. J. Appl. Earth Obs. Geoinf. 35 (PB), 239-246.

Boardman, J.W., Kruse, F.A., Green, R.O., 1995. Mapping target signatures via partial unmixing of AVIRIS data. In: Summaries of the 5th JPL Airborne Earth Science Workshop. JPL Publication, Pasadena, California, pp. 23-26.

Brewer, C.K., Winne, J.C., Redmond, R.L., Opitz, D.W., Mangrich, M.V., 2005. Classifying and mapping wildfire severity: a comparison of methods. Photogramm. Eng. Remote. Sens. 71, 1311-1320.

Cansler, C.A., McKenzie, D., 2012. How robust are burn severity indices when applied in a new region? Evaluation of alternate field-based and remote-sensing methods. Remote Sens. 4, 456-483.

Chander, G., Markham, B.L., Helder, D.L., 2009. Summary of current radiometric calibration coefficients for Landsat MSS, TM, ETM +, and EO-1 ALI sensors. Remote Sens. Environ. 113, 893-903.

Chavez Jr, P.S., 1988. An improved dark-object subtraction technique for atmospheric scattering correction of multispectral data. Remote Sens. Environ. 24, 459-479.

Chavez Jr., P.S., 1989. Radiometric calibration of Landsat thematic mapper multispectral images. Photogramm. Eng. Remote. Sens. 55, 1285-1294.

Chavez Jr., P.S., 1996. Image-based atmospheric corrections — revisited and improved. Photogramm. Eng. Remote. Sens. 62, 1025-1036.

Chen, G., Metz, M.R., Rizzo, D.M., Meentemeyer, R.K., 2015. Mapping burn severity in a disease-impacted forest landscape using Landsat and MASTER imagery. Int. J. Appl. Earth Obs. Geoinf. 40, 91-99.

Chu, T., Guo, X., Takeda, K., 2016. Temporal dependence of burn severity assessment in Siberian larch (Larix sibirica) forest of northern Mongolia using remotely sensed data. Int. J. Wildland Fire 25 (6), 685-698.

Chuvieco, E., 2009. In: Chuvieco, E. (Ed.), Global Impacts of Fire in Earth Observation of Wildland Fires in Mediterranean Ecosystems. Springer, pp. 1-10.

Chuvieco, E., Riaño, D., Danson, F.M., Martín, M.P., 2006. Use of a radiative transfer model to simulate the post-fire spectral response to burn severity. J. Geophys. Res. Biogeosci. 111, http://dx.doi.org/10.1029/2005JG000143.
Chuvieco, E., De Santis, A., Riaño, D., Halligan, K., 2007. Simulation approaches for burn severity estimation using remotely sensed images. J. Fire Ecol. 3, 129-150.

Cocke, A.E., Fulé, P.Z., Crouse, J.E., 2005. Comparison of burn severity assessments using differenced normalized burn ratio and ground data. Int. J. Wildland Fire 14, 189-198.

Congalton, R.G., 1991. A review of assessing the accuracy of classifications of remotely sensed data. Remote Sens. Environ. 37, 35-46.

Costa, P., Castellnou, M., Larrañaga, A., Miralles, M., Kraus, D., 2011. Prevention of Large Wildfires Using the Fire Types Concept Fire Paradox. European Forest Institute.

de Santis, A., Chuvieco, E., 2007. Burn severity estimation from remotely sensed data: performance of simulation versus empirical models. Remote Sens. Environ. $108,422-435$.

de Santis, A., Chuvieco, E., 2009. GeoCBI: a modified version of the composite burn index for the initial assessment of the short-term burn severity from remotely sensed data. Remote Sens. Environ. 113, 554-562.

de Santis, A., Chuvieco, E., Vaughan, P., 2009. Short-term assessment of burn severity using the inversion of PROSPECT and GeoSail models. Remote Sens. Environ. $113,126-136$

Dennison, P.E., Roberts, D.A., 2003. Endmember selection for mapping chaparral species and fraction using multiple endmember spectral mixture analysis. Remote Sens. Environ. 41, 123-135.

Dennison, P.E., Halligan, K.Q., Roberts, D.A., 2004. A comparison of error metrics and constraints for multiple endmember spectral mixture analysis and spectral angle mapper. Remote Sens. Environ. 93, 359-367.

Drake, N.A., Mackin, S., Settle, J.J., 1999. Mapping vegetation, soils, and geology in semiarid shrublands using spectral matching and mixture modelling of SWIR AVIRIS imagery. Remote Sens. Environ. 68, 12-25.

Dudley, K.L., Dennison, P.E., Roth, K.L., Roberts, D.A., Coates, A.R., 2015. A multi-temporal spectral library approach for mapping vegetation species across spatial and temporal phenological gradients. Remote Sens. Environ. 167, 121-134.

Fang, L., Yang, J., 2014. Atmospheric effects on the performance and threshold extrapolation of multi-temporal Landsat derived dNBR for burn severity assessment. Int. J. Appl. Earth Obs. Geoinf. 33, 10-20.

Fernández-Manso, A., Quintano, C., 2015. Evaluating Landsat ETM + emissivity-enhanced spectral indices for burn severity discrimination in Mediterranean forest ecosystems. Remote Sens. Lett. 6, 302-310.

Fernández-Manso, O., Quintano, C., Fernández-Manso, A., 2009. Combining spectral mixture analysis and object-based classification for fire severity mapping. Forest Sys. 18, 296-313.

Fernández-Manso, A., Quintano, C., Roberts, D., 2012. Evaluation of potential of multiple endmember spectral mixture analysis (MESMA) for surface coal mining affected area mapping in different world forest ecosystems. Remote Sens. Environ. 127, 181-193.

Franke, J., Roberts, D.A., Halligan, K., Menz, G., 2009. Hierarchical multiple endmember spectral mixture analysis (MESMA) of hyperspectral imagery for urban environments. Remote Sens. Environ. 113, 1712-1723.

Frolking, S., Palace, M.W., Clark, D.B., Chambers, J.Q., Shugart, H.H., Hurtt, G.C., 2009. Forest disturbance and recovery: a general review in the context of spaceborne remote sensing of impacts on aboveground biomass and canopy structure. J. Geophys. Res. G: Biogeosci. 114, G00E02. http://dx.doi.org/10.1029/ 2008JG000911.

Gilabert, M.A., Conese, C., Maselli, F., 1994. An atmospheric correction method for the automatic retrieval of surface reflectance from TM images. Int. J. Remote Sens. 15, 2065-2086.

Grillo, F., Castellnou, M., Molina, D., Martinez, E., Diaz, D., 2008. Análisis del Incendio Forestal: PLANIFICACIÓN DE LA Extinción. (Ediciones AIFEMA).

Guccione, P., Mascolo, L., Appice, A., 2015. Iterative hyperspectral image classification using spectral-spatial relational features. IEEE Trans. Geosci. Remote Sens. 53, 3615-3627

Harris, S., Veraverbeke, S., Hook, S., 2011. Evaluating spectral indices for assessing fire severity in chaparral ecosystems (Southern California) using MODIS/ASTER (MASTER) airborne simulator data. Remote Sens. 3, 2403-2419.

Hogland, J., Billor, N., Anderson, N., 2013. Comparison of standard maximum likelihood classification and polytomous logistic regression used in remote sensing. Eur. Can. J. Remote. Sens. 46, 623-640.

Hosmer Jr., D.W., Lemeshow, S., Sturdivant, R.X., 2013. Logistic Regression Models for Multinomial and Ordinal Outcomes, in Applied Logistic Regression, third ed. John Wiley \& Sons, Inc., Hoboken, NJ, USA.

Hudak, A., Morgan, P., Bobbitt, M., Smith, A., Lewis, S., Lentile, L., Robichaud, P., Clark, J., McKinley, R., 2007. The relationship of multispectral satellite imagery to immediate fire effects. Fire Ecology 3, 64-90.

Jiménez-Muñoz, J.C., Sobrino, J.A., 2003. A generalized single-channel method for retrieving land surface temperature from remote sensing data. J. Geophys. Res. 108, 4688-4695.

Jiménez-Muñoz, J.C., Cristobal, J., Sobrino, J.A., Soria, G., Ninyerola, M., Pons, X., 2009. Revision of the single-channel algorithm for land surface temperature re 
trieval from Landsat thermal-infrared data. IEEE Trans. Geosci. Remote Sens. 47, 339-349.

Kane, V.R., Lutz, J.A., Roberts, S.L., Smith, D.F., McGaughey, R.J., 2013. Landscape-scale effects of fire severity on mixed-conifer and red fir forest structure in Yosemite National Park. For. Ecol. Manag. 287, 17-31.

Kane, V.R., North, M.P., Lutz, J.A., Churchill, D.J., Roberts, S.L., Smith, D.F., McGaughey, R.J., Kane, J.T., Brooks, M.L., 2014. Assessing fire effects on forest spatial structure using a fusion of Landsat and airborne LiDAR data in Yosemite National Park. Remote Sens. Environ. 151, 89-101.

Kasischke, E., Hoy, E.E., French, N.H.F., Turetsky, M.R., 2007. Post-fire evaluation of the effects of fire on the environment using remotely-sensed data. In: Gitas, I., Carmona, C. (Eds.), Towards an Operacional Use of Remote Sensing in Forest Fire Management. Office for Official Publications of the European Communities, Luxembourg, pp. 34-52.

Keshava, N., Mustard, J.F., 2002. Spectral Unmixing. 2. IEEE Processing Magazine, 44-57.

Key, C.H., Benson, N.C., 2006. Landscape assessment: ground measure of severity, the composite burn index; and remote sensing of severity, the normalized burn ratio. In: Lutes, D.C., Keane, R.E., Caratti, J.F., Key, C.H., Benson, N.C., Sutherland, S., Gangi, L.J. (Eds.), FIREMON: Fire Effects Monitoring and Inventory System. USDA Forest Service, Rocky Mountain Research Station, Ogden, UT, pp. 1-51. Gen. Tech. Rep. RMRS-GTR-164-CD: LA.

Kolden, C.A., Smith, A.M.S., Abatzoglou, J.T., 2015. Limitations and utilisation of monitoring trends in burn severity products for assessing wildfire severity in the USA. Int. J. Wildland Fire 24, 1023-1028.

Koutsias, N., Karteris, M., 2000. Burned area mapping using logistic regression modeling of a single post-fire Landsat- 5 thematic mapper image. Int. J. Remote Sens. 21, 673-687.

Lambin, E., Goyvaerts, K., Petit, C., 2003. Remotely-sensed indicators of burning efficiency of savannah and forest fires. Int. J. Remote Sens. 24, 3105-3118.

Lentile, L., Holden, Z., Smith, A., Falkowski, M., Hudak, A., Morgan, P., Lewis, S., Gessler, P., Benson, N., 2006. Remote sensing techniques to assess active fire characteristics and post-fire effects. Int. J. Wildland Fire 15, 319-345.

Lentile, L., Smith, A., Hudak, A., Morgan, P., Bobbitt, M., Lewis, S., Robichaud, P., 2009. Remote sensing for prediction of 1-year post-fire ecosystem condition. Int. J. Wildland Fire 18, 594-608.

Marchetti, A., Piccini, C., Santucci, S., Chiuchiarelli, I., Francaviglia, R., 2011. Simulation of soil types in Teramo province (Central Italy) with terrain parameters and remote sensing data. Catena $85,267-273$.

Maselli, F., 1998. Multiclass spectral decomposition of remotely sensed scenes by selective pixel unmixing. IEEE Trans. Geosci. Remote Sens. 36, 1809-1820.

Miller, J.D., Thode, A.E., 2007. Quantifying burn severity in a heterogeneous landscape with a relative version of the delta normalized burn ratio (dNBR). Remote Sens. Environ. 109, 66-80.

Miller, J.D., Knapp, E.E., Key, C.H., Skinner, C.N., Isbell, C.J., Creasy, R.M., Sherlock, J.W., 2009. Calibration and validation of the relative differenced normalized burn ratio (RdNBR) to three measures of fire severity in the Sierra Nevada and Klamath Mountains, California, USA. Remote Sens. Environ. 113, 645-656.

Montealegre, A.L., Lamelas, M.T., Tanase, M.A., de la Riva, J., 2014. Forest fire severity assessment using ALS data in a Mediterranean environment. Remote Sens. 6, 4240-4265.

Morgan, P., Keane, R.E., Dillon, G.K., Jain, T.B., Hudak, A.T., Karau, E.C., Sikkink, P.G., Holden, Z.A., Strand, E.K., 2014. Challenges of assessing fire and burn severity using field measures, remote sensing and modeling. Int. J. Wildland Fire 23, 1045-1060.

Mulder, V.L., de Bruina, S., Weyermannb, J., Kokaly, R.F., Schaepmana, M.E., 2013. Characterizing regional soil mineral composition using spectroscopy and geostatistics. Remote Sens. Environ. 139, 415-429.

Osborne, J.W., 2014. Best Practices in Logistic Regression.

Parker, B.M., Lewis, T., Srivastava, S.K., 2015. Estimation and evaluation of multi-decadal fire severity patterns using Landsat sensors. Remote Sens. Environ. $170,340-349$.

Parks, S.A., Dillon, G.K., Miller, C., 2014. A new metric for quantifying burn severity: the relativized burn ratio. Remote Sens. 6, 1827-1844.

Prabhakar, M., Prasad, Y.G., Desai, S., Thirupathi, M., Gopika, K., Rao, G.R., Venkateswarlu, B., 2013. Hyperspectral remote sensing of yellow mosaic severity and associated pigment losses in Vigna mungo using multinomial logistic regression models. Crop. Prot. 45, 132-140.

Prabhakar, M., Prasad, Y.G., Vennila, S., Thirupathi, M., Sreedevi, G., Rao, G.R., Venkateswarlu, B., 2013. Hyperspectral indices for assessing damage by the solenopsis mealybug (Hemiptera: Pseudococcidae) in cotton. Comput. Electron. Agric. 97, 61-70.

Pyne, S.J., 1996. Introduction to Wildland and Rural Fire. Princeton University Press, Princeton, NJ (654p).

Qin, Z., Karnieli, A., Berliner, P., 2001. A mono-algorithm for retrieving land surface temperature from Landsat TM data and its application to the Israel-Egypt border region. Int. J. Remote Sens. 22, 583-594.
Quintano, C., Fernández-Manso, A., Shimabukuro, Y.E., Pereira, G., 2012. Spectral unmixing: a review. Int. J. Remote Sens. 33, 5307-5340.

Quintano, C., Fernández-Manso, A., Roberts, D.A., 2013. Multiple endmember spectral mixture analysis (MESMA) to map burn severity levels from Landsat images in Mediterranean countries. Remote Sens. Environ. 136, 76-88.

Quintano, C., Fernández-Manso, A., Calvo, L., Marcos, E., Valbuena, L., 2015. Land surface temperature as potential indicator of burn severity in forest Mediterranean ecosystems. Int. J. Appl. Earth Obs. Geoinf. 36, 1-12.

Roberts, D.A., Smith, M.O., Adams, J.B., 1993. Green vegetation nonphotosynthetic vegetation and soils in AVIRIS data. Remote Sens. Environ. 44, 255-269.

Roberts, D.A., Gardner, M., Church, R., Ustin, S., Scheer, G., Green, R.O., 1998. Mapping chaparral in the Santa Monica Mountains using multiple endmember spectral mixture models. Remote Sens. Environ. 65, 267-279.

Roberts, D.A., Dennison, P.E., Gardner, M., Hetzel, Y., Ustin, S.L., Lee, C., 2003. Evaluation of the potential of Hyperion for fire danger assessment by comparison to the airborne visible/infrared imaging spectrometer. IEEE Trans. Geosci. Remote Sens. 41, 1297-1310

Roberts, D.A., Halligan, K., Dennison, P., 2007. VIPER Tools User Manual. V1.5.

Roberts, D.A., Quattrochi, D.A., Hulley, G.C., Hook, S.J., Green, R.O., 2012. Synergies between VSWIR and TIR data for the urban environment: an evaluation of the potential for the hyperspectral infrared imager (HyspIRI) decadal survey mission. Remote Sens. Environ. 117, 83-101.

Roberts, D.A., Dennison, P.E., Roth, K.L., Dudley, K., Hulley, G., 2015. Relationships between dominant plant species, fractional cover and land surface temperature in a Mediterranean ecosystem. Remote Sens. Environ. 167, 152-167.

Roth, K.L., Dennison, P.E., Roberts, D.A., 2012. Comparing endmember selection techniques for accurate mapping of plant species and land cover using imaging spectrometer data. Remote Sens. Environ. 127, 139-152.

Roy, D.P., Boschetti, L., Trigg, S.N., 2006. Remote sensing of fire severity: assessing the performance of the normalized burn ratio. IEEE Trans. Geosci. Remote Sens. 3, 112-116.

Schaaf, A.N., Dennison, P.E., Fryer, G.K., Roth, K.L., Roberts, D.A., 2011. Mapping plant functional types at multiple spatial resolutions using imaging spectrometer data. GIScience Remote Sens. 48, 324-344.

Schmuck, G., San-Miguel-Ayanz, J., Camia, T., Durrant, T., Boca, R., Libertá, G., 2012. Forest Fires in Europe, Middle East and North Africa 2012. Reference report by the Joint Research Centre of the European Commission. (118 pp).

Schmuck, G., San-Miguel-Ayanz, J., Camia, A., Durrant, T., Boca, R., Libertá, G., Petroliagkis, T., di Leo, M., Rodrigues, D., Boccaci, F., 2014. Forest fires in Europe, Middle East and North Africa 2013. In: JCR Scientific and Technical Reports. Joint Research Centre. Institute for Environment and Sustainability. JRC91373. $118 \mathrm{pp}$.

Shimabukuro, Y.E., Smith, J., 1991. The least-squares mixing models to generatefraction images derived from remote sensing multispectral data. IEEE Trans. Geosci. Remote Sens. 29, 16-21.

Smith, A., Wooster, M., Drake, N., Dipotso, F., Falkowski, M., Hudak, A., 2005. Testing the potential of multi-spectral remote sensing for retrospectively estimating fire severity in African savannahs. Remote Sens. Environ. 97, 92-115.

Sobrino, J.A., Li, Z.-L., Stoll, M.P., 1993. Impact of the atmospheric transmittance andtotal water vapor content in the algorithms for estimating satellite sea surface temperatures. IEEE Trans. Geosci. Remote Sens. 31, 946-952.

Sobrino, J.A., Jiménez-Muñoz, J.C., Sòria, G., Romaguera, M., Guanter, L., Moreno, J., Plaza, A., Martínez, P., 2008. Land surface emissivity retrieval from different VNIR and TIR sensors. IEEE Trans. Geosci. Remote Sens. 48, 316-327.

Somers, B., Zortea, M., Plaza, A., Asner, G.P., 2012. Automated extraction of image-based endmember bundles for improved spectral unmixing. In: IEEE Journal of Selected Topics in Applied Earth Observations and Remote Sensing. 5, pp. 396-408.

Soverel, N.O., Perrakis, D.D.B., Coops, N.C., 2010. Estimating burn severity from Landsat dNBR and RdNBR indices across western Canada. Remote Sens. Environ. 114, 1896-1909.

Soverel, N.O., Coops, N.C., Perrakis, D.D.B., Daniels, L.D., Gergel, S.E., 2011. The transferability of a dNBR-derived model to predict burn severity across 10 wildland fires in western Canada. Int. J. Wildland Fire 20, 518-531.

Sparks, A.M., Boschetti, L., Smith, A.M.S., Tinkham, W.T., Lannom, K.O., Newingham, B.A., 2015. An accuracy assessment of the MTBS burned area product for shrub-steppe fires in the northern Great Basin, United States. Int. J. Wildland Fire 24 (1), 70-78.

Stambaugh, M.C., Hammer, L.D., Godfrey, R., 2015. Performance of burn-severity metrics and classification in oak woodlands and grasslands. Remote Sens. 7, 10501-10522.

Sunderman, S.O., Weisberg, P.J., 2011. Remote sensing approaches for reconstructing fire perimeters and burn severity mosaics in desert spring ecosystems. Remote Sens. Environ. 115, 2384-2389.

Tan, K., Hua, J., Li, J., Duc, P., 2015. A novel semi-supervised hyperspectral image classification approach based on spatial neighborhood information and classifier combination. ISPRS J. Photogramm. Remote Sens. 105, 19-29. 
Tanase, M., de la Riva, J., Pérez-Cabello, F., 2011. Estimating burn severity in Aragón pine forest using optical based indices. Can. J. For. Res. 41, 863-872.

Teillet, P.M., Guindon, B., Goodenough, D.G., 1982. On the slope-aspect correction of multispectral scanner data. Can. J. Remote. Sens. 8, 84-106.

Thorp, K.R., French, A.N., Rango, A., 2013. Effect of image spatial and spectral characteristics on mapping semi-arid rangeland vegetation using multiple endmember spectral mixture analysis (MESMA). Remote Sens. Environ. 132, 120-130.

Tompkins, S., Mustard, J.F., Pieters, C.M., Forsyth, D.W., 1997. Optimization of endmembers for spectral mixture analysis. Remote Sens. Environ. 59, 472-489.

Vasques, G.M., Demattê, J.A.M., Viscarra-Rossel, R.A., Ramírez-López, L., Terra, F.S., Rizzo, R., DeSouza-Filho, R., 2015. Integrating geospatial and multi-depth laboratory spectral data for mapping soil classes in a geologically complex area in southeastern Brazil. Eur. J. Soil Sci. 66, 767-779.

Veraverbeke, S., Hook, S.J., 2013. Evaluating spectral indices and spectral mixture analysis for assessing fire severity, combustion completeness and carbon emissions. Int. J. Wildland Fire 22, 707-720.

Veraverbeke, S., Van de Kerchove, R., Verstraeten, W., Lhermitte, S., Goossens, R., 2010. Fire-induced changes in vegetation, albedo and land surface temperature assessed with MODIS. In: Remote Sensing for Science, Education, and Natural and Cultural Heritage: Proceedings of the EARSeL Symposium. 2010, pp. 431-438.

Veraverbeke, S., Harris, S., Hook, S., 2011. Evaluating spectral indices for burned area discrimination using MODIS/ASTER (MASTER) airborne simulator data. Remote Sens. Environ. 115, 2702-2709.

Veraverbeke, S., Hook, S., Hulley, G., 2012. An alternative spectral index for rapid fire severity assessments. Remote Sens. Environ. 123, 72-80.

Veraverbeke, S., Hook, S.J., Harris, S., 2012. Synergy of VSWIR $(0.4-2.5 \mu \mathrm{m})$ and MTIR (3.5-12.5 $\mu \mathrm{m})$ data for post-fire assessments. Remote Sens. Environ. 124, $771-779$.

Veraverbeke, S., Verstraeten, W.W., Lhermitte, S., Van de Kerchove, R., Goossens, R., 2012. Assessment of post-fire changes in land surface temperature and surface albedo, and their relation with fire-burn severity using multitemporal MODIS imagery. Int. J. Wildland Fire 21, 243-256.

Veraverbeke, S., Stavros, E.N., Hook, S.J., 2014. Assessing fire severity using imaging spectroscopy data from the airborne visible/infrared imaging spectrometer (AVIRIS) and comparison with multispectral capabilities. Remote Sens. Environ. 154, 153-163.

Vlassova, L., Pérez-Cabello, F., Rodrigues, M., Montorio, R., García-Martín, A., 2014 Analysis of the relationship between land surface temperature and wildfire severity in a series of Landsat images. Remote Sens. 6, 6136-6162.

Waser, L.T., Küchler, M., Jütte, K., Stampfer, T., 2014. Evaluating the potential of WorldView-2 data to classify tree species and different levels of ash mortality. Remote Sens. 6, 4515-4545.

Wendt, C., Beringer, J., Tapper, N., Hutley, L., 2007. Local boundary-layer development over burnt and unburnt tropical savanna: an observational study. Bound.-Layer Meteorol. 124, 291-304.

Wu, Z., Middleton, B., Hetzler, R., Vogel, J., Dye, D., 2015. Vegetation burn severity mapping using Landsat-8 and WorldView-2. Photogramm. Eng. Remote. Sens. 81 (2), 143-154.

Youngentob, K.N., Roberts, D.A., Held, A.A., Dennison, P.E., Jia, X., Lindenmayer, D.B., 2011. Mapping two Eucalyptus subgenera using multiple endmember spectral mixture analysis and continuum-removed imaging spectrometry data. Remote Sens. Environ. 115, 1115-1128.

Zeilhofer, P., 2006. Soil mapping in the Pantanal of Mato Grosso, Brazil, using multitemporal Landsat TM data. Wetl. Ecol. Manag. 14, 445-461.

Zheng, Z., Zeng, Y., Li, S., Huang, W., 2016. A new burn severity index based on land surface temperature and enhanced vegetation index. Int. J. Appl. Earth Obs. Geoinf. 45, 84-94. 